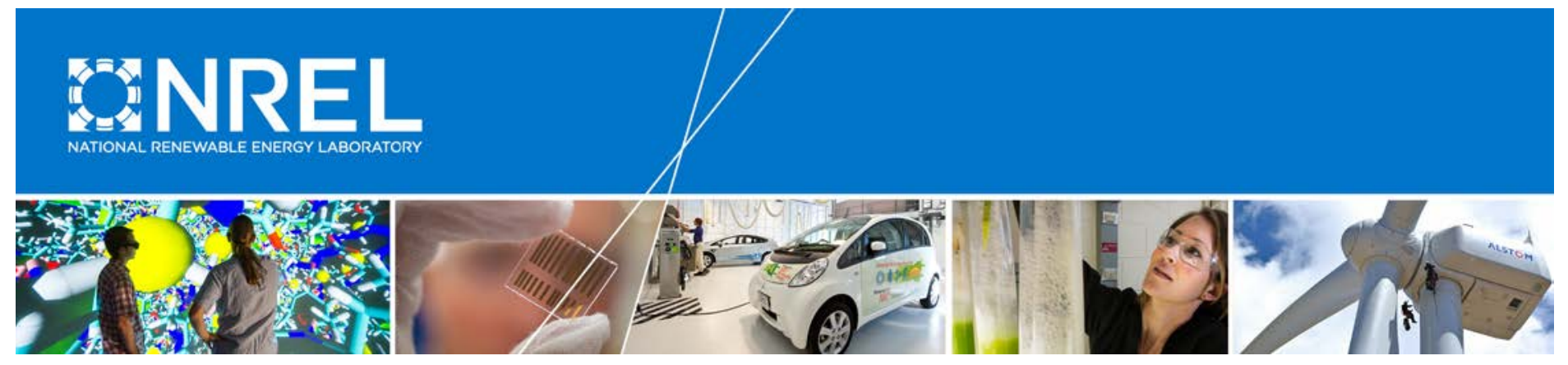

\title{
Capacity Payments in Restructured Markets under Low and High Penetration Levels of Renewable Energy
}

Thomas Jenkin, Philipp Beiter, and Robert Margolis National Renewable Energy Laboratory

NREL is a national laboratory of the U.S. Department of Energy Office of Energy Efficiency \& Renewable Energy Operated by the Alliance for Sustainable Energy, LLC

This report is available at no cost from the National Renewable Energy Laboratory (NREL) at www.nrel.gov/publications.

Technical Report

NREL/TP-6A20-65491

February 2016 


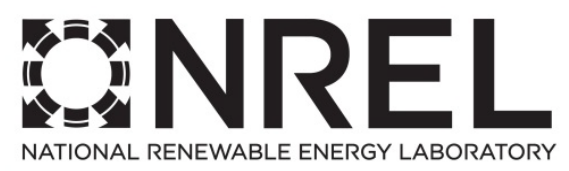

\section{Capacity Payments in Restructured Markets under Low and High Penetration Levels of Renewable Energy}

Thomas Jenkin, Philipp Beiter, and Robert Margolis National Renewable Energy Laboratory

Prepared under Task No. SA15.0500

NREL is a national laboratory of the U.S. Department of Energy Office of Energy Efficiency \& Renewable Energy Operated by the Alliance for Sustainable Energy, LLC

This report is available at no cost from the National Renewable Energy Laboratory (NREL) at www.nrel.gov/publications.

National Renewable Energy Laboratory 15013 Denver West Parkway Golden, CO 80401 303-275-3000 • www.nrel.gov
Technical Report

NREL/TP-6A20-65491

February 2016

Contract No. DE-AC36-08GO28308 


\section{NOTICE}

This report was prepared as an account of work sponsored by an agency of the United States government. Neither the United States government nor any agency thereof, nor any of their employees, makes any warranty, express or implied, or assumes any legal liability or responsibility for the accuracy, completeness, or usefulness of any information, apparatus, product, or process disclosed, or represents that its use would not infringe privately owned rights. Reference herein to any specific commercial product, process, or service by trade name, trademark, manufacturer, or otherwise does not necessarily constitute or imply its endorsement, recommendation, or favoring by the United States government or any agency thereof. The views and opinions of authors expressed herein do not necessarily state or reflect those of the United States government or any agency thereof.

This report is available at no cost from the National Renewable Energy Laboratory (NREL) at www.nrel.gov/publications.

Available electronically at SciTech Connect http:/www.osti.gov/scitech

Available for a processing fee to U.S. Department of Energy and its contractors, in paper, from:

U.S. Department of Energy

Office of Scientific and Technical Information

P.O. Box 62

Oak Ridge, TN 37831-0062

OSTI http://www.osti.gov

Phone: 865.576.8401

Fax: 865.576.5728

Email: reports@osti.gov

Available for sale to the public, in paper, from:

U.S. Department of Commerce

National Technical Information Service

5301 Shawnee Road

Alexandria, VA 22312

NTIS http://www.ntis.gov

Phone: 800.553 .6847 or 703.605 .6000

Fax: 703.605.6900

Email: orders@ntis.gov 


\section{Acknowledgments}

The authors would first like to thank those we interviewed from a number of organizations about the successes and challenges facing restructured markets. We agreed not to list the interviewed individuals or their organizations to encourage candid discussions. We would also like to thank the following for providing substantive comments that improved the structure and content of the paper: Stephen Capanna, Caitlin Callaghan, Paul Donohoo-Vallett, Ookie Ma, Ramteen Sioshansi, Doug Arent, Aaron Bloom, Paul Denholm, Gian Porro, Michael Milligan, David Mooney, Connie Komomua, Mike Meshek, and Jarett Zuboy. We also gratefully acknowledge funding for this work from the Solar Energy Technologies Office and the Office of Strategic Programs of the U.S. Department of Energy's Office of Energy Efficiency and Renewable Energy under contract number DE-AC36-08GO28308. 


\section{List of Acronyms}

\begin{tabular}{|c|c|}
\hline APPA & American Public Power Association \\
\hline AS & Ancillary services \\
\hline CAISO & California Independent System Operator \\
\hline CCGT & Combined-cycle gas turbine \\
\hline $\mathrm{CT}$ & Combustion turbine \\
\hline EIA & U.S. Energy Information Administration \\
\hline ERCOT & Electric Reliability Council of Texas \\
\hline FCA & Forward capacity auction \\
\hline FCM & Forward capacity market \\
\hline FERC & Federal Energy Regulatory Commission \\
\hline FIT & Feed-in tariff \\
\hline ICAP & Installed (summer) capacity \\
\hline IRM & Installed reserve margin \\
\hline ISO & Independent system operator \\
\hline ISO-NE & ISO New England \\
\hline LCOE & Levelized cost of electricity (LCOE) \\
\hline LDA & Locational deliverability area \\
\hline MISO & Midcontinent Independent System Operator \\
\hline MMU & Market monitoring unit \\
\hline Net CONE & Net cost of new entry \\
\hline NYISO & New York Independent System Operator \\
\hline PPA & Power-purchase agreement \\
\hline PRM & Planning reserve margin \\
\hline PTC & Production tax credit \\
\hline PV & Photovoltaic \\
\hline RM & Reserve margin \\
\hline RPM & Reliability Pricing Model \\
\hline RTO & Regional transmission organization \\
\hline SPP & Southwest Power Pool \\
\hline UCAP & Unforced capacity \\
\hline VRE & Variable renewable energy \\
\hline VRR & Variable resource requirement \\
\hline
\end{tabular}




\section{Abstract}

There is considerable debate about the degree to which restructured markets perform successfully in their use of capacity markets. In providing appropriate incentives for new and existing generation to meet reliability requirements, a variety of capacity market designs have developed across regional transmission organizations and independent system operators in the United States and internationally. Growing levels of variable renewable energy (VRE) resources arguably create new challenges for capacity market designs, because VRE suppresses wholesale energy prices while providing relatively little capacity. This effect becomes more pronounced the higher the VRE penetration in a market. The purpose of this report is threefold. First, we provide a brief outline of the purpose and design of various capacity markets using administratively determined capacity demand curves. Second, we discuss some of the main challenges raised in existing literature and a set of interviews that we conducted with market participants, regulators, and observers. Third, we consider some of the challenges to capacity markets that arise with higher VRE penetration. As part of our discussion, we provide context from Germany's experience addressing some of these challenges that may arise under high VRE penetration. The "merit order" effect from VRE can be expected to suppress wholesale energy prices and revenue for existing generation and new entrants, which may be mitigated to some degree by increased capacity payments and greater reliance on ancillary services payments for flexible capacity. Greater reliance on capacity markets for generator revenues may amplify any inefficiency and costs associated with capacity price volatility and suboptimal market design choices. Regulatory intervention to ensure adequate capacity payments and ancillary services revenue may become more prevalent and challenging than under current market designs as the timescale for market signals shifts increasingly from near term (e.g., day-ahead in wholesale electricity markets) to longer term (e.g., annual intervals in capacity markets). Our review and discussion with market participants suggest challenges may remain in implementing capacity markets that provide both adequate operational and investment incentives, particularly under high-VRE scenarios with greater need for flexible capacity. 


\section{Table of Contents}

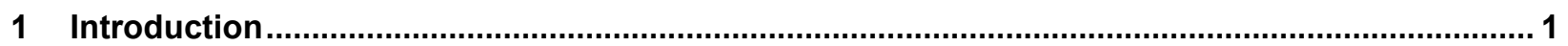

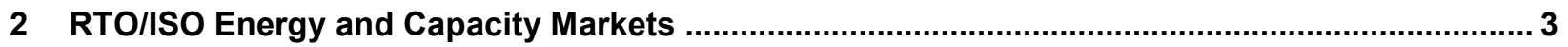

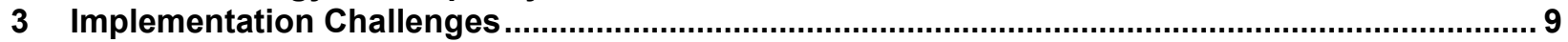

3.1 Auction Price Volatility for Capacity and Capital Recovery .................................................... 9

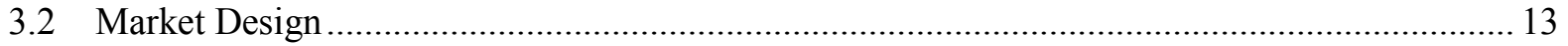

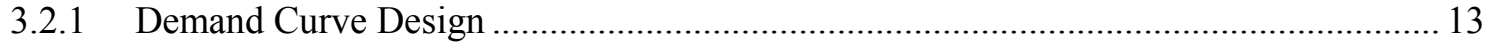

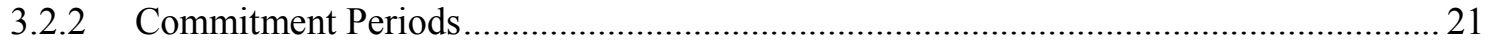

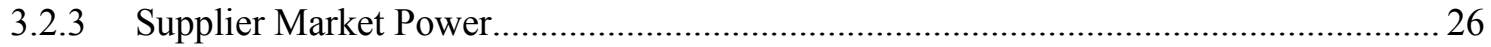

3.2.4 Impact of Stakeholder Interests, Political Intervention, and Interconnection Issues...... 27

4 Additional Challenges for Systems with High VRE Penetration Levels ................................. 28

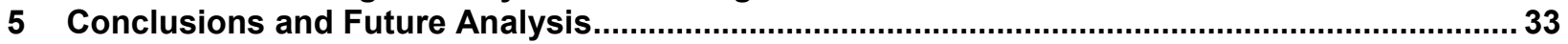

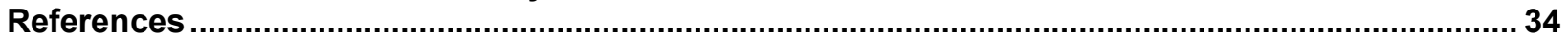




\section{List of Figures}

Figure 1. VRR demand curve for PJM used in 2011 for 2014/15 Base Residual Auction.......................... 6

Figure 2. Variation in shape of VRR capacity demand curves across RTOs and over time........................ 8

Figure 3. Capacity payments for different RTOs/ISOs and select sub-regions for commitment periods

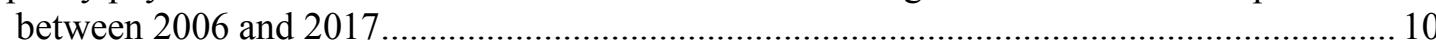

Figure 4. RPM Base Residual Auction Resource Clearing Prices within PJM over time and by sub-region (LDA).

Figure 5. Fraction of target annual capital recovery for new CCGTs and CTs in PJM based on realized energy and AS net revenue and capacity payments (whose price was set 3 years prior to delivery)

Figure 6. Variation of VRR curve across PJM over time

Figure 7. Actual natural gas prices for the electric sector and differences between actual and projected natural gas prices in the delivery year using 1) historical 3-year average prices, and 2) forward prices, both estimated 3 years in advance of the delivery year.

Figure 8. Existing and new capacity that cleared and missed out in UK 2014 capacity auction for 2018/19.

Figure 9. PJM capacity clearing prices ( $\$$ MW-day) by region

Figure 10. German wholesale electricity prices (Phelix Base, monthly averages) for 2008-2015 and estimated ranges for levelized cost of electricity (LCOE) of fossil fuel power plants constructed in 2013

\section{List of Tables}

Table 1. Overview of Capacity Markets across U.S. RTOs/ISOs 4

Table 2. Breakdown of Incremental Capacity Additions in PJM from 2007/2008 to 2018/2019 18

\section{List of Text Boxes}

Text Box 1. Germany: A Market with High VRE Penetration 


\section{Introduction}

In many regional transmission organizations (RTOs) and independent system operators (ISOs) ${ }^{1}$ across the United States, capacity markets are considered necessary for ensuring resource adequacy in restructured wholesale markets. Capacity markets can be defined as "a means of providing revenue to owners of power plants who in return agree to stand ready to supply power when needed" (APPA 2015a). The capacity payments associated with capacity markets are intended to correct a set of market failures, collectively referred to as the "missing money" effect, which reflect factors such as low demand flexibility, a relatively inelastic supply, and price caps (Cramton et al. 2013). Capacity payments allow plant owners to recover those capital and other costs that cannot be recovered through electricity sales in wholesale energy and ancillary markets (APPA 2015a).

This report provides an overview of various capacity markets and discusses a range of challenges arising from both market design choices and higher variable renewable energy (VRE) penetration levels. It does not provide a comprehensive analysis of the various challenges in specific market regions but rather focuses on some of the most critical issues currently faced by policymakers and electricity market participants. Specifically, the report discusses issues that may be relevant to many markets, such as the value and duration of capacity payments, estimates of the values and shape of the capacity demand curve, mitigation strategies for pivotal supplier market power, and whether existing and new generation should receive different capacity incentives. We identified these challenges based on interviews with market participants, regulators, and observers as well as a review of the relevant literature. The latter includes recent reviews by Spees et al. (2013), which examined U.S. capacity market behavior over the past decade, and Bowring (2013) for $\mathrm{PJM}^{2}$ as well as studies that range widely in their views of the nature and success of capacity markets (e.g., Borenstein and Bushnell 2001, 2015; Joskow 2001, 2008; Blumsack et al. 2006; Lave et al. 2007; Caplan 2012; Bowring 2013; Cramton et al. 2013; Ela et al. 2014; Milligan et al. 2014; Pfeifenberger et al. 2014; Newell and Spees 2014a, 2014b; BNEF 2015; Bhagwat et al. 2016; Ela et al. 2016; Milligan et al. 2016).

The consideration of higher VRE penetration levels with respect to capacity payments is important, because VRE can suppress energy prices while providing relatively little capacity (Felder 2011). This can impact compensation and associated incentives for new and existing conventional thermal generation ${ }^{3}$ significantly. The effect can be amplified by the existence of federal and state incentive mechanisms for renewable energy, such as renewable portfolio standards or production tax credits (PTCs) in the United States or feed-in tariffs (FITs) in other international markets. In several markets with high penetrations of VRE, such as Germany, this price-suppression effect and its impact on existing generation have been widely discussed (e.g.,

\footnotetext{
${ }^{1}$ RTOs or ISOs "are independent, membership-based, non-profit organizations that ensure reliability and optimize supply and demand bids for wholesale electric power. In 2009, U.S. RTOs managed $60 \%$ of the power supplied to load serving entities. In other parts of the country, electricity systems are operated by individual utilities or utility holding companies" (EIA 2011). There are seven RTOs/ISOs in the United States and a total of 10 in North America (EIA 2011).

${ }^{2} \mathrm{PJM}$ is an RTO that coordinates the movement of wholesale electricity in all or parts of 13 states and the District of Columbia (http://www.pjm.com/).

${ }^{3}$ Conventional thermal generation refers to dispatchable generation that uses a heat source, including coal (pulverized), nuclear, natural gas-fired combustion turbine (CT), and combined-cycle gas turbine (CCGT) plants. Unlike VRE, its variable fuel cost is not zero.
} 
Traber and Kemfert 2011, Weiss 2014, DIW 2014). Our discussion of the interaction of capacity market designs and different VRE penetration levels in U.S. electricity markets can help inform the ongoing debate on market adaption and associated tradeoffs.

The report is divided into three main parts:

- Section 2 introduces the basic economic theory behind the use and implementation of capacity payments in restructured markets, including a discussion of the variations among capacity demand curves (commonly referred to as variable resource requirement [VRR] demand curves) in PJM, ISO New England (ISO-NE), and New York ISO (NYISO).

- Sections 3 and 4 summarize observations across RTO markets and identify some key challenges as reflected in the wider literature and expressed in the interviews we conducted, including those associated with higher VRE penetration levels.

- Section 5 concludes and suggests areas for further analysis to resolve some of the issues identified in Sections 3 and 4. 


\section{RTO/ISO Energy and Capacity Markets}

In designing capacity markets, ISO/RTO market authorities follow three general objectives as defined by the Federal Energy Regulatory Commission (FERC 2014), namely that markets provide 1) reasonable returns for producers, 2) at just and reasonable costs for energy services, while 3) meeting system reliability targets. In meeting these objectives, a variety of different electricity and capacity market designs have evolved as part of a wider market restructuring process initiated in the mid-1990s (Borenstein and Bushnell 2001, 2015). The variation in capacity market designs can be ascribed to a combination of factors specific to individual markets and path dependency, including differences in stakeholder processes and interests, settlement procedures, system characteristics, and history.

Under traditional utility regulation regimes, resource adequacy is met by load-serving entities obtaining regulatory approval for their portfolio of resources. Investor-owned and publically owned, vertically integrated utilities are monopolies that recover their costs from customers at a reasonable return on investment as determined in rate cases. In restructured wholesale markets, the generators that supply power face a comparatively higher financial risk for long-term investments, because cost recovery is no longer guaranteed (FERC 2013, p.2). The requirements to meet reserve margins (RMs) for unforced installed capacity are often $15 \%$ or higher (NERC 2015). ${ }^{4}$ This situation, in combination with wholesale market price caps, lack of demand-side response, and out-of-market interventions by system operators or regulators, leads to the commonly described "missing money" problem (Borenstein and Bushnell 2001, 2015; Joskow 2008; Spees et al. 2013; Felder 2011; Cramton et al. 2013), where the net revenue from energy and ancillary services (AS) is not sufficient for full capital cost recovery. An existing generator or potential new entrant faced with such a "missing money" situation may no longer be able to recover costs from energy and AS revenue alone on an expected basis. These risks to investments on a standalone basis or as part of a portfolio may be amplified by the uncertainties associated with regulatory intervention. This includes consideration of the past, current, and future impact of technology-specific policies and subsidies, such as the use of PTCs or FITs for VRE or decisions related to the building, operation, and retirement of fossil and nuclear generation. In evaluating the merit of these regulatory interventions, an entire set of additional policy goals may be taken into account, including their role in internalizing external costs, such as those associated with carbon dioxide emissions. The outlook of higher financial risks and suppressed energy prices in restructured markets has raised concerns about economic efficiency and reliability among some market participants, regulators, and other observers. In order to address these concerns, capacity markets were introduced across several RTO/ISO markets beginning in the mid-2000s to procure sufficient amounts of capacity resources. Table 1 provides an overview of capacity markets currently implemented across RTOs/ISOs.

\footnotetext{
${ }^{4}$ The North American Electric Reliability Corporation assigns a 15\% RM for predominantly thermal systems (NERC 2015).
} 
Table 1. Overview of Capacity Markets across U.S. RTOs/ISOs

\begin{tabular}{|c|c|c|c|c|c|}
\hline & PJM & MISO $^{a}$ & ISO-NE & NYISO & CAISO $^{b}$ \\
\hline First auction & $2007 / 8$ & $2013 / 14$ & $2010 / 11$ & $2006 / 7$ & 2016 \\
\hline Forward period & 3 years & $\begin{array}{l}\text { Short term }(\sim 2 \\
\text { months) }\end{array}$ & 3 years & $\begin{array}{l}\text { Short term ( 2- } \\
30 \text { days) }\end{array}$ & Short term \\
\hline $\begin{array}{l}\text { Commitment } \\
\text { period }\end{array}$ & 1 year & 1 year & 1 year & $\begin{array}{l}6 \text { months or for } \\
\text { specific month }\end{array}$ & $\mathrm{N} / \mathrm{A}$ \\
\hline \multirow[t]{2}{*}{ Procurement } & - Bilateral & - Bilateral & - Bilateral & - Bilateral & - Bilateral \\
\hline & $\begin{array}{l}\text { - Mandatory } \\
\text { auction }\end{array}$ & $\begin{array}{l}\text { - Voluntary } \\
\text { auction }\end{array}$ & $\begin{array}{l}\text { - Mandatory } \\
\text { auction }\end{array}$ & $\begin{array}{l}\text { - Voluntary \& } \\
\text { mandatory } \\
\text { auction }\end{array}$ & $\begin{array}{c}\text { - "Back stop" } \\
\text { capacity }{ }^{5} \text { at } \\
\text { fixed price }\end{array}$ \\
\hline
\end{tabular}

${ }^{a} \mathrm{MISO}=$ Midcontinent ISO

${ }^{\mathrm{b}}$ CAISO = California ISO; CAISO has resource adequacy requirements for load-serving entities and can procure capacity on a "backstop" basis, but it is commonly not considered to operate a capacity market in a strict sense.

There are two other RTOs/ISOs in the United States-the Electric Reliability Council of Texas (ERCOT) and the Southwest Power Pool (SPP)—which do not have capacity markets. ${ }^{6}$

Source: BNEF (2015) and Spees et al. (2013).

Based on several key features of capacity market design identified by FERC (2013), we briefly describe core market design elements relevant for our discussion in Section 3. This discussion largely focuses on centralized capacity markets. ${ }^{7}$

In determining the amount of capacity to meet the planning RM (PRM) ${ }^{8}$ at "just and reasonable rates" (FERC 2013), RTOs/ISOs have implemented administratively determined demand curves for capacity that reflect an estimated demand at associated price levels. Supply curves for capacity are based on bids for generation capacity and demand-side resource commitment from suppliers. Capacity markets clear at the intersection of supply and demand. The supply curve can be expected to increase sharply at the point where existing generation and demand-side resource capacity transition to new generation. ${ }^{9}$ A variety of auction processes have been established in RTO/ISO regions (e.g., multiple-round descending clock, ascending clock, and sealed bid auctions) that require load-serving entities to either self-supply capacity or participate in their

\footnotetext{
${ }^{5}$ CAISO has made provisions to move towards a market-based auction in 2016 (BNEF 2015).

${ }^{6}$ The two RTOs without capacity markets in the Unites States are ERCOT and SPP, which covers all or parts of 14 states in the central United States. ERCOT relies on an energy-only market, whereas SPP has a relatively high RM of 48\% in 2014 (SPP MMU 2015). As the SPP market monitoring unit (MMU) notes in its 2014 State of the Market report, "Other RTOs have experienced a 'missing money problem' in energy markets, where net revenues do not support needed new investments. SPP had a high, 48\%, resource margin for 2014, so the MMU does not expect net revenue to cover the cost of new investment. SPP prices for the first year of the Integrated Marketplace were high enough to support ongoing operation and maintenance costs of new efficient generators dispatched economically" (SPP MMU 2015).

${ }^{7}$ More details can be found in a number of references, including Spees et al. (2013) and Bowring (2013).

${ }^{8} \mathrm{~A}$ PRM is designed to measure the amount of generation capacity available to meet expected demand in a planning horizon (NERC 2015).

${ }^{9}$ This upward kink in the supply curve when transitioning from existing to new generation capacity may be a result of sunk capital costs from existing generation.
} 
local capacity auction market. Generators with capacity bidding offers that are competitive (less than or equal to the clearing price) all receive the same market clearing price.

Demand curves for future capacity in PJM, ISO-NE, and NYISO are based on the net cost of new entry (net CONE) for a specified reference technology. A recent market monitoring report for ISO-NE provides a useful description of the goals and mechanisms for forward capacity markets (FCMs) and how these relate to the net CONE concept (Patton et al. 2015):

The Forward Capacity Market $(\mathrm{FCM})^{10}$ is designed to attract and maintain sufficient resources to satisfy ISO-NE's long-term resource planning requirements efficiently. FCM provides economic signals that supplement the signals provided by the energy and ancillary services markets. In combination, these three sources of revenue provide economic signals for new investment, retirement decisions, and participation by demand response.

Forward Capacity Auctions [FCAs] are held roughly 3 years before the beginning of each year-long Capacity Procurement Period to provide sufficient lead time for a new generator to be built if its offer is accepted in an FCA. Nine FCAs have been held [in ISO-NE] so far, which have facilitated the procurement of installed capacity for the capacity periods ending May 2019.

Capacity markets are generally designed to provide incentives for efficient investment in new resources. A prospective investor estimates the cost of investment over the life of the project minus the expected variable profits from providing energy and ancillary services (after netting the associated variable costs). This difference between investment costs and variable profits, which is known as Net Cost of New Entry (net CONE), is the estimated capacity revenue that would be necessary for the investment to be profitable.

Net CONE is based on a reference technology, which is often a gas-fired simple-cycle CT, though there has been substantive discussion about whether the use of a CCGT or a technology mix may be more appropriate (Pfeifenberger et al. 2014). These estimates are determined for a future online date of the power plant, which corresponds to the respective commitment period of the capacity auction (Newell et al. 2014). While net CONE serves as the basis for the demand curve, actual capacity payments from a single auction depend on the clearing price, which is set by the intersection of supply and demand. The fraction of net CONE that is paid for capacity provision ranges from a significant premium (to net CONE), if supply is short relative to the target RM, to a value at or close to zero when supply is sufficiently long (Patton et al. 2014):

In an efficient market, the investments with the lowest Net CONE will be the first to occur. The capacity price should clear at a level that is higher than the Net CONE of the investments that are needed and lower than the Net CONE of investments that are not needed. In this manner, the market facilitates investment in efficient capacity resources to meet system planning requirements. The resulting clearing price provides a signal to the market of the value of capacity. [Emphasis added.]

\footnotetext{
${ }^{10}$ FCMs have different names across RTOs. For instance, in PJM the capacity auction process is called the Reliability Pricing Model (RPM) Base Residual Auction.
} 
The administratively determined demand curve for PJM is shown in Figure 1, which is commonly referred to as the VRR demand curve. As explained by Bowring (2013):

The highest price part of the demand curve is flat from the y or price axis at a price equal to 1.5 times the net cost of new entry, or the gross cost of new entry if that is higher. The flat portion extends to point [a], where the quantity equals the reliability requirement ${ }^{11}$ less approximately three percent. The curve slopes downward to point $[b]$, where the price is the net cost of new entry. The quantity at point $[\mathrm{b}]$ is the reliability requirement plus approximately one percent [IRM + $1 \%$ ]. The curve slopes downward to point [c] where the price is 20 percent of the net cost of new entry. The quantity at point [c] is the reliability requirement plus approximately five percent [IRM $+5 \%]$. The demand curve drops to the $\mathrm{x}$ axis from point [c].... The demand curve shown in [Figure 1] is for the entire RTO without accounting for locational differences. There are separate supply and demand curves for each LDA [locational deliverability area] with a potentially binding transmission constraint.

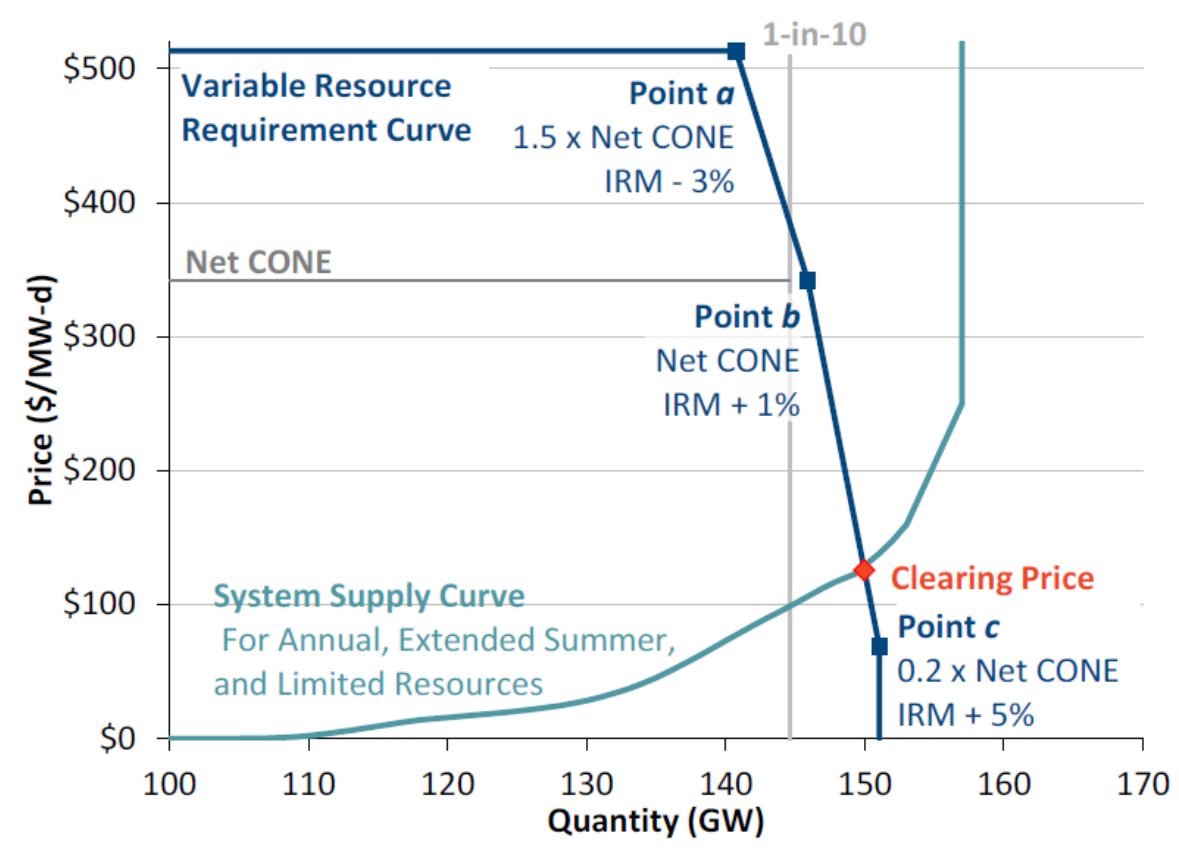

Figure 1. VRR demand curve for PJM used in 2011 for 2014/15 Base Residual Auction

IRM = installed RM; VRR curve reflects the system VRR curve in the 2014/15 PJM Planning Parameters. The supply curve reflects all supply offers for Annual, Extended Summer, and Limited Resources, stacked in order of offer price and smoothed for illustrative purposes.

Source: Figure and notes from Pfeifenberger et al. (2014).

\footnotetext{
${ }^{11}$ The reliability requirement in this PJM illustration is defined by a resource adequacy analysis that applies a Loss
} of Load Expectation (LOLE) of one occurrence in 10 years (indicated by the vertical line "1-in-10" in Figure 1). 
Multiple choices must be made when implementing or changing the design of a capacity market, and these choices likely reflect stakeholder interest, past decisions, and the status quo. Some key parameters associated with implementing a VRR demand curve include a determination of:

\section{Demand Curve}

- A price and quantity for the target RM (Point "b" in Figure 1) at X percentage points above the IRM needed to satisfy the system-wide reliability requirement

- The shape and slope of the VRR demand curve

- The choice of reference technology for calculating net CONE

- Temporal basis for net CONE estimation: realized vs. projected values.

\section{Forward and Commitment Periods}

- Forward period: years auction for capacity held in advance of future delivery year

- Commitment period: capacity delivery period, typically 1 year, but may be longer in some RTOs/ISOs and/or circumstances (e.g., may be different for new vs. existing generation).

\section{Definition of the Capacity Product}

- Differentiation between operational capabilities of capacity resources (e.g., different commitment periods for capacity resources)

- Appropriate capacity market regions.

\section{Supply Curve}

- Treatment of solar and wind as capacity resources and their contribution to setting and achieving the target RM.

Table 1 summarizes some variation in these key parameters across RTOs/ISOs. ${ }^{12}$ Figure 2 shows the different shapes and slopes of VRR curves in ISO-NE, NYISO, and PJM (current and proposed as of 2014). The x-axis RM has been normalized so the target RM is 1.0. For PJM, as described above for the then "current" VRR curve, net CONE is 1.0 when $1 \%$ above the target RM. However, ISO-NE and NYISO have considerably lower gradients and intersect the $\mathrm{x}$-axis at higher values above the target RM. As discussed in Section 3, PJM later joined this trend by both shifting the curve to the right and introducing a convex rather than a concave or linear shape of the demand curve. We will refer to these key parameters in Section 3 when analyzing various challenges across markets and assessing the impact of high VRE penetration levels.

\footnotetext{
${ }^{12}$ A more detailed discussion can be found in BNEF (2015) and Spees et al. (2013).
} 


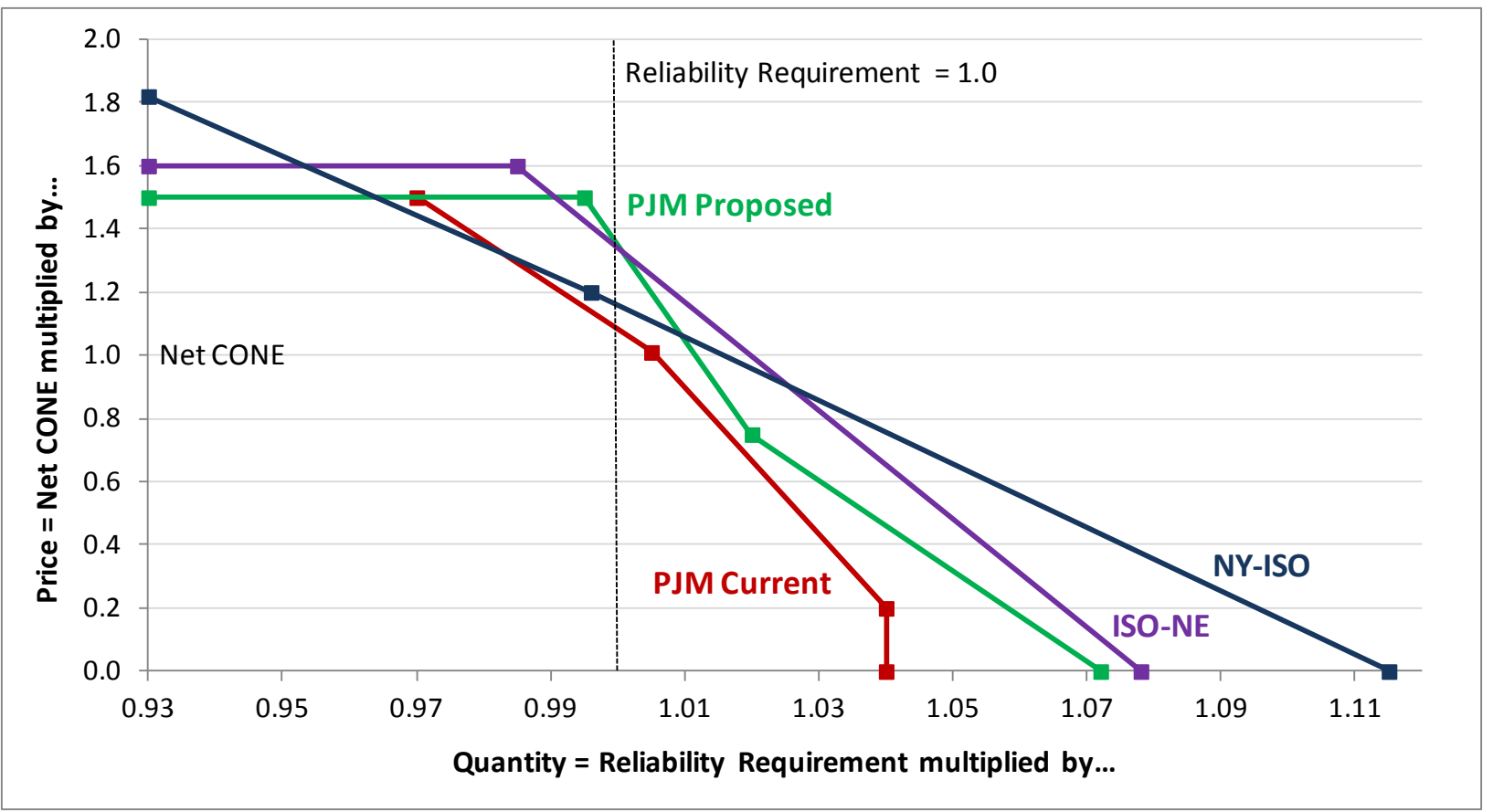

Figure 2. Variation in shape of VRR capacity demand curves across RTOs and over time Source: Redrawn from PJM (2014b). 


\section{Implementation Challenges}

In the prior section, we outlined some key parameters of capacity markets with an application to VRR curves to meet reliability targets. In this section, we assess challenges-identified in interviews and the broader literature - that have been encountered in implementing this reliability-based pricing methodology in capacity markets. ${ }^{13}$ As a mechanism to address longterm resource adequacy, capacity markets can arguably deliver their benefits (and costs) only over a longer time horizon (Cramton and Ockenfels 2012). However, as noted in a recent PJM market monitoring report, efficient market design and implementation require a continuous effort to adapt to the dynamics of market evolution and mitigate regulatory imperfections (Monitoring Analytics 2014):

Wholesale power markets are defined by complex rules. Markets do not automatically provide competitive and efficient outcomes. There are still areas of market design that need further improvement in order to ensure that the PJM markets continue to adapt successfully to changing conditions. The details of market design matter.

In Section 3.1, we address auction price volatility and capital recovery observed across some capacity markets. An analysis of the challenges associated with different market design parameters then follows in Section 3.2. For each of the market design parameters, we briefly raise the relevant issues and choices, and we discuss views of different participants, or relevant literature, including some observations by market monitors.

\subsection{Auction Price Volatility for Capacity and Capital Recovery}

Prices from capacity market auctions introduced in the mid-2000s have been highly volatile from the beginning. Figure 3 shows the variation in prices for capacity payments for the delivery commitment periods between 2006 and 2017 for ISO-NE, PJM, and NYISO. For instance, in PJM and NYISO (with the New York City sub-region excluded), capacity clearing prices varied by more than a factor of five in some of their recent auctions, with similar volatility observed in other markets. Figure 4 shows that, in addition to high volatility for any given RTO/ISO, there may also be a wide variation in capacity prices within sub-regions (known in PJM as LDAs). This volatility of capacity prices is a persistent concern with the design and operation of capacity markets. High price volatility (in any market) translates into higher levels of uncertainty about future revenue. In turn, this results in higher investment risk and uncertainty and, ultimately, higher consumer costs. This situation may be particularly critical for the electric sector because of the long-term and capital-intensive nature of investments in this sector. Some of our interviewees expressed the concern that — by design — capacity markets established a misalignment between the greater net revenue certainty needed for long-term investments and the short-term fluctuations in prices from annually held capacity market auctions, effectively discouraging investment.

\footnotetext{
${ }^{13}$ For a more detailed discussion, see, e.g., Blumsack et al. (2006), Caplan (2012), Spees et al. (2013), Bowring (2013), Cramton et al. (2013), and various RTO market monitoring reports such as Monitoring Analytics (2014, 2015) and Patton et al. (2014, 2015).
} 


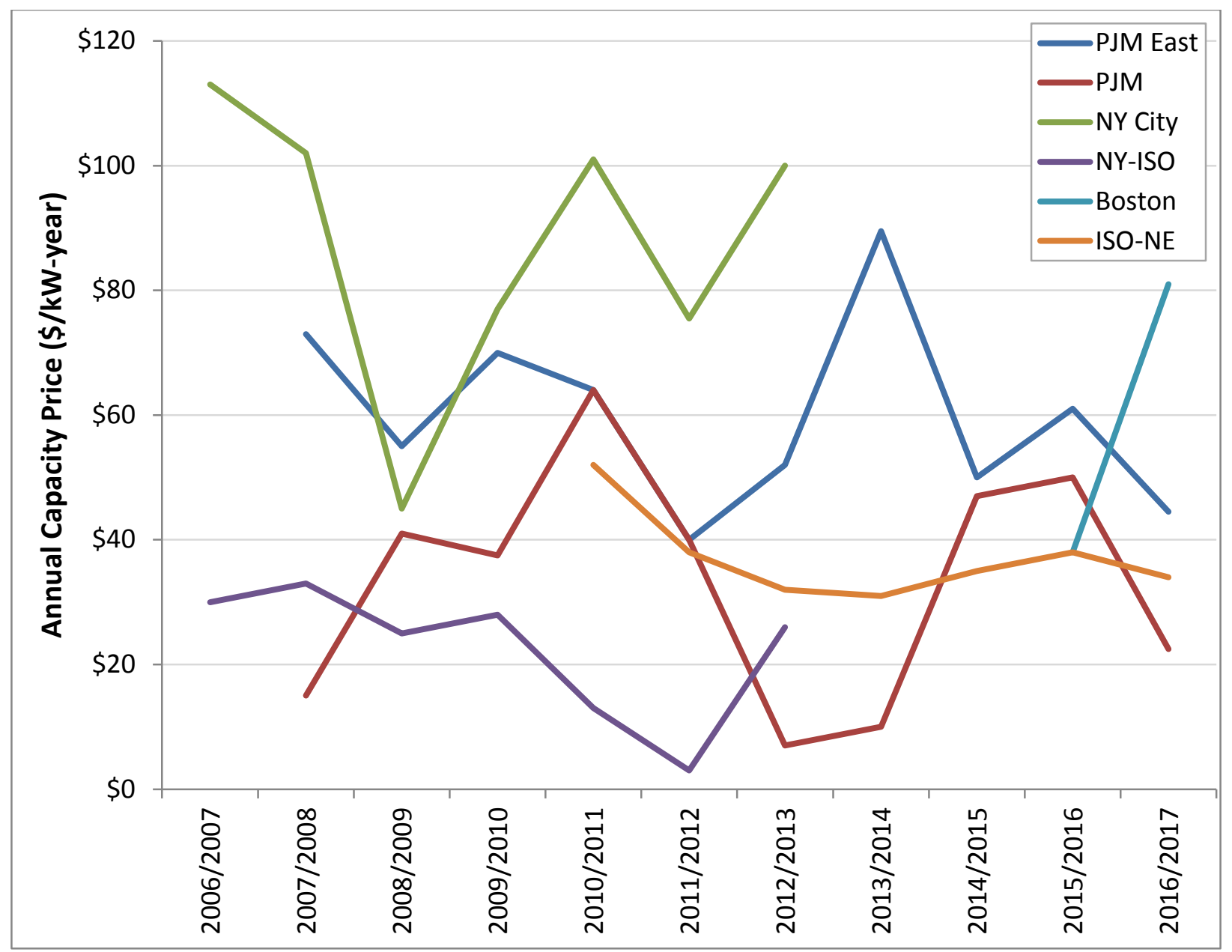

Figure 3. Capacity payments for different RTOs/ISOs and select sub-regions for commitment periods between 2006 and 2017

Source: FERC (2013) 


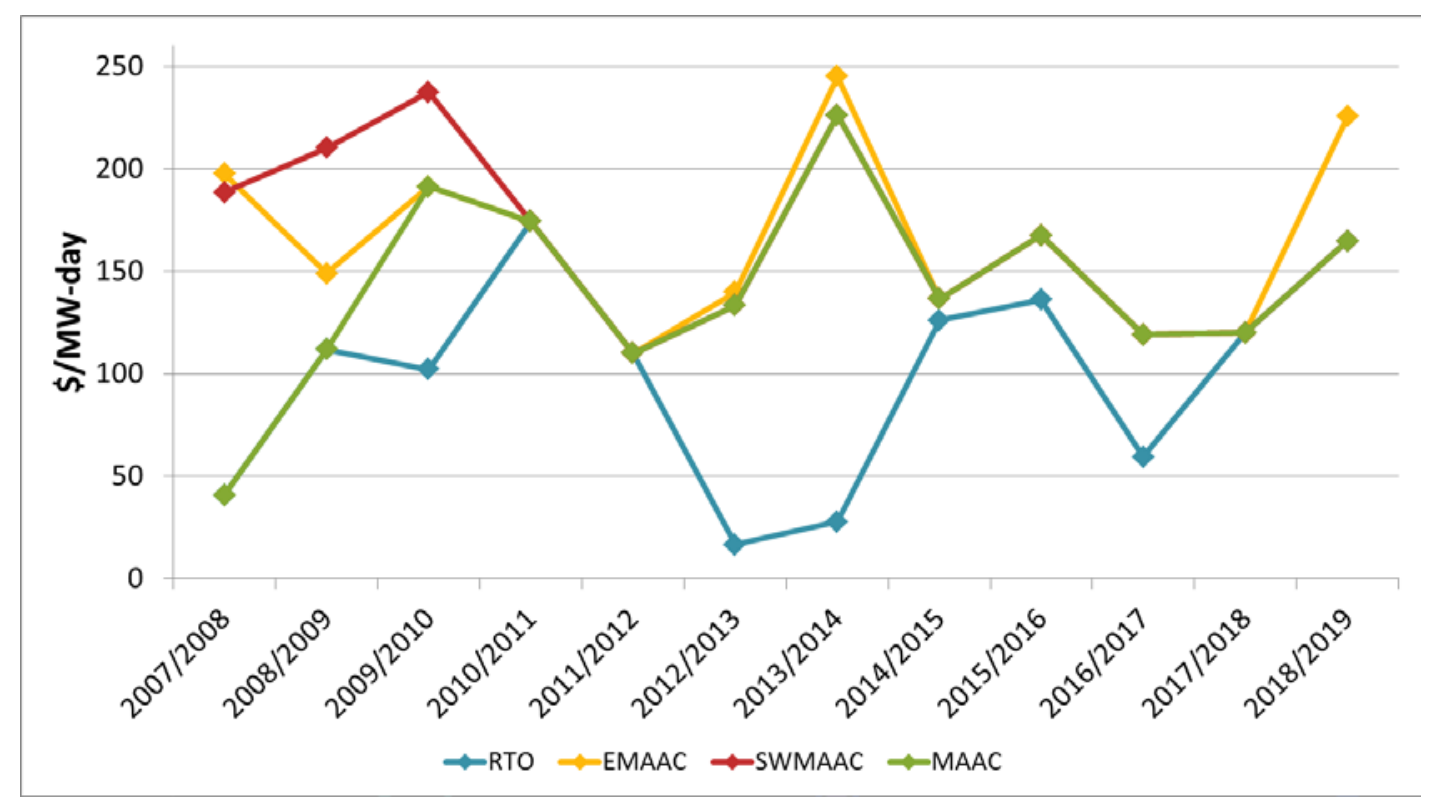

Figure 4. RPM Base Residual Auction Resource Clearing Prices within PJM over time and by subregion (LDA)

Source: Based on PJM (2015); 2014/2015 through 2018/2019 prices reflect the Annual Resource Clearing Prices.

Spees et al. (2013) attribute this volatility to three factors. First, capacity prices depend on underlying market fundamentals, such as load growth, costs of incremental supply, environmental compliance requirements, and energy market prices (and the fossil prices that underlie them). Arguably, these factors should be at least partly reflected in year-to-year clearing prices to incentivize accurate levels of capacity supply (however, see Section 3.2.1 for a discussion about challenges arising with the lag between capacity price setting and the delivery period). Second, volatility stems from ongoing rule changes implemented in capacity markets (e.g., changes to the VRR demand curves, including changes in their shape or the incorporation of previously excluded demand resources). Third, "administrative patterns"-such as load forecasts, CONE estimates, or import constraints - may contribute to capacity price and net revenue volatility. In addition, FERC (2013) mentions a "lumpiness" problem, which refers to the observation that capacity additions may be larger than annual clearing prices could be expected to stimulate. This results from the size of conventional power projects, which on average have been built with an installed capacity that is typically $200 \mathrm{MW}$ or more for a CT and 450-500 MW or more for a CCGT in recent years. This additional capacity may exceed the incremental capacity needs, which may in turn "inhibit efficient entry of new capacity resources even when supplies are below the planning reserve margin" (FERC 2013). Smaller regions, therefore, may face a potential tradeoff between region-specific pricing signals and the larger impact of incremental capacity on the RM. This may also increase the likelihood of raising potential market power issues with pivotal suppliers. 
Until recently there has been considerable concern over whether capacity payments were sufficient to provide the right incentives to new and (perhaps) existing generation. Figure 5 shows for PJM (for each year between 2009 and 2014) the degree to which the sum of the realized net CONE in the delivery year and the actual net energy and AS revenue met the annualized capital requirements for a CT and CCGT. A coverage value of 1.0 indicates a new unit would earn its rate of return. Two points are worth noting. First, the CCGT coverage is greater than that for the CTs over the entire period shown. This raises the question of whether CCGTs may be being overpaid relative to CTs, which for PJM is the reference technology for net CONE. This greater coverage may also have led to more capacity of new CCGTs being built over this period - as is discussed in more detail in Section 3.2.1. However, the coverage across all years considered here is relatively low. While this may be in part due to the capacity supply being long relative to the target RM, it may also reflect energy and AS revenue being lower than anticipated when the capacity payments were set owing to market design issues. As noted by the PJM market monitoring report for 2013 (Monitoring Analytics 2014):

It is more critical than ever to get capacity market prices correct. A number of capacity market design elements have resulted in a substantial suppression of capacity market prices for multiple years. The impact in the 2016/2017 base auction was about $\$ 4.6$ billion. That price suppression has had and continues to have a negative impact on net revenues and thus on the incentive to continue to operate existing units and to invest in new units. Price suppression is more acute in western zones than in eastern zones.

Price suppression leads to premature and uneconomic retirements and the failure to make economic investments. Coal units and nuclear units are under stress in PJM markets. The MMU [market monitoring unit] estimates that the actual net revenue results for 2013 mean that 14,597 MW of capacity in PJM are at risk of retirement in addition to the $24,933 \mathrm{MW}$ that are currently planning to retire. [Emphasis added.]

Potential issues may include the effect of much lower natural gas prices since 2008 due to the growing but (at the time) unexpected production of U.S. shale gas. This would not have been factored into a net CONE estimation made 3 years before the delivery year and based on an average of historical natural gas prices at the time. Such potential underpayment in the past may have influenced recent changes in the shape of the VRR curve that have favored higher payments when supply is $0 \%-5 \%$ above the target RM. Section 3.2 discusses these issues in more detail. 


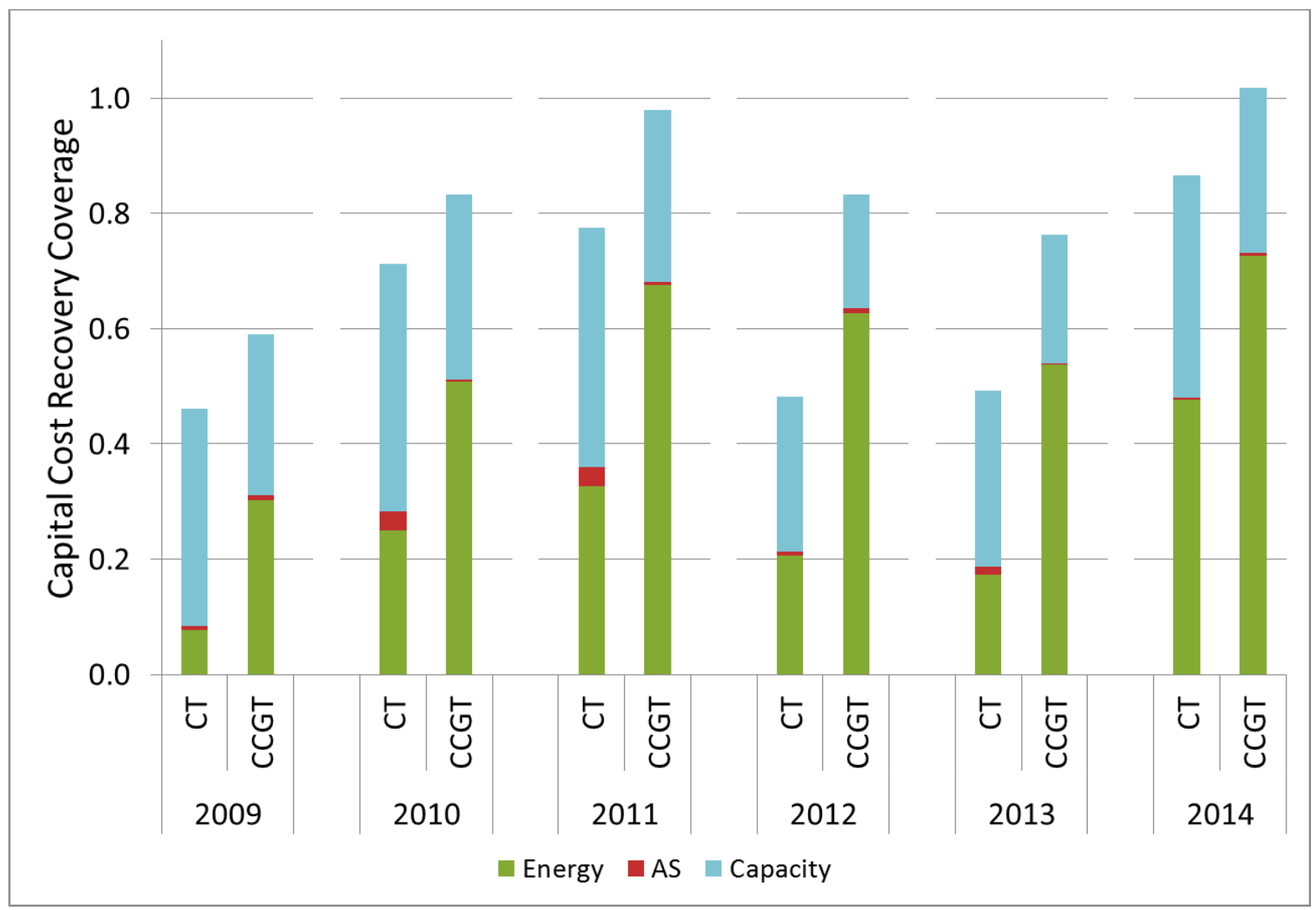

Figure 5. Fraction of target annual capital recovery for new CCGTs and CTs in PJM based on realized energy and AS net revenue and capacity payments (whose price was set 3 years prior to delivery)

Source: Based on calculations and data in Monitoring Analytics (2015).

\subsection{Market Design}

The challenges mentioned below are organized into a number of broad areas corresponding to the key parameters identified in Section 2. While we recognize that these areas are interrelated, we address each of them individually.

\subsubsection{Demand Curve Design}

Our discussion of demand curve design challenges relates to the shape and slope of the VRR demand curve, the choice of net CONE reference technologies, and the choice of historical vs. forward-looking methods for estimating net CONE.

\section{Shape and Slope of the VRR Demand Curve}

As discussed in Section 2, the VRR demand curve intends to provide a capacity payment in excess of net CONE when supply falls short and less than net CONE when supply is abundant. The capacity price (set by the clearing price where supply matches demand) captures the fraction of net CONE that suppliers realize above or below net CONE. If the supply quantity cleared is short compared to the target RM, the VRR demand curve often sets the capacity price at a net CONE multiple of 1.5 to 2 (the "price cap") to signal scarcity of capacity supply (Figure 2). If 
supply in the market is abundant, this net revenue offset is typically much less than net CONE to signal that additional capacity is not encouraged.

There continues to be debate over the value and shape of the VRR demand curve. In some RTOs/ISOs, earlier VRR demand curves had a slope near the target RM at or close to "vertical" and featured a sudden drop-off to zero (or some low fraction of net CONE) at an RM slightly above the target (e.g., 1\%). ${ }^{14}$ A common concern with vertical or near-vertical VRR demand curves is that they may lead to highly volatile capacity payments and increase the potential for the exercise of market power by pivotal suppliers. This volatility is largely a result of steep supply curve inflection occurring at a capacity supply value where the VRR demand curve is declining rapidly. The upward kink of the supply curve can be attributed to "low going-forward costs from the existing generation fleet and considerably higher going-forward costs from new supplies" (Spees et al. 2013). In addition, when supply is only slightly long, the clearing price would wrongly indicate the value of existing capacity is zero (Patton et al. 2014). Similarly there might be problems with the present value of the future net capacity payments being biased low over the life of the asset, if the market on a decadal basis tends to remain long on average rather than short (as seems to be anticipated in many U.S. markets). PJM and NYISO have long relied on downward-sloping VRR demand curves, which are commonly expected to reduce capacity price volatility. Recently, ISO-NE adopted the use of a similar curve in its ninth auction in 2015; specifically it replaced "the current vertical demand curve with a sloped demand curve that recognizes that excess capacity above the minimum planning reserve requirement provides additional benefits in the forms of increased reliability and lower energy and ancillary services prices" (ISO-NE 2015b). The market monitoring report for ISO-NE (Patton et al. 2015) noted:

Sloped demand curves are essential for capacity markets to perform well and establish efficient clearing prices. Sloped demand curves have been used successfully in the PJM and NYISO capacity markets. In addition to establishing more efficient capacity prices, sloped demand curves also: a) reduce capacity price volatility, which reduces investment risk and lowers the cost of entry; and b) improve market competitiveness by reducing the price effects of withholding capacity.

On the other hand, Spees et al. (2013) note that "a very flat slope can exacerbate supply surplus, and very more problematically can lead to supply shortage conditions." Recent decisions in PJM further illustrate the ongoing debate about VRR demand curve shapes. The concern over adequate capacity payments for existing and new generation may have led PJM to propose a VRR demand curve that has a much shallower slope $\left(\frac{\Delta \$ / k W-y e a r}{\Delta \% R M}\right)$ so that prices for capacity extend well beyond the target RM. In a 2014 decision for the 2018/2019 capacity auction to be held in 2015, PJM reduced the gradient and shifted the VRR demand curve to the right (Figure 6). PJM explained the reasoning for its decision (PJM 2014a):

With current and proposed air emissions regulations, uncertainty over the status of demand response resources in the capacity market, and other factors expected to influence a significant change in coming years in the composition of the portfolio

\footnotetext{
${ }^{14}$ Where the RM requirement was chosen to reflect a 1 in 10 (1 day in 10 years) loss of load event.
} 
of resources on which the PJM region depends for reliability, the proposed VRR curve strikes a prudent balance of cost and reliability.

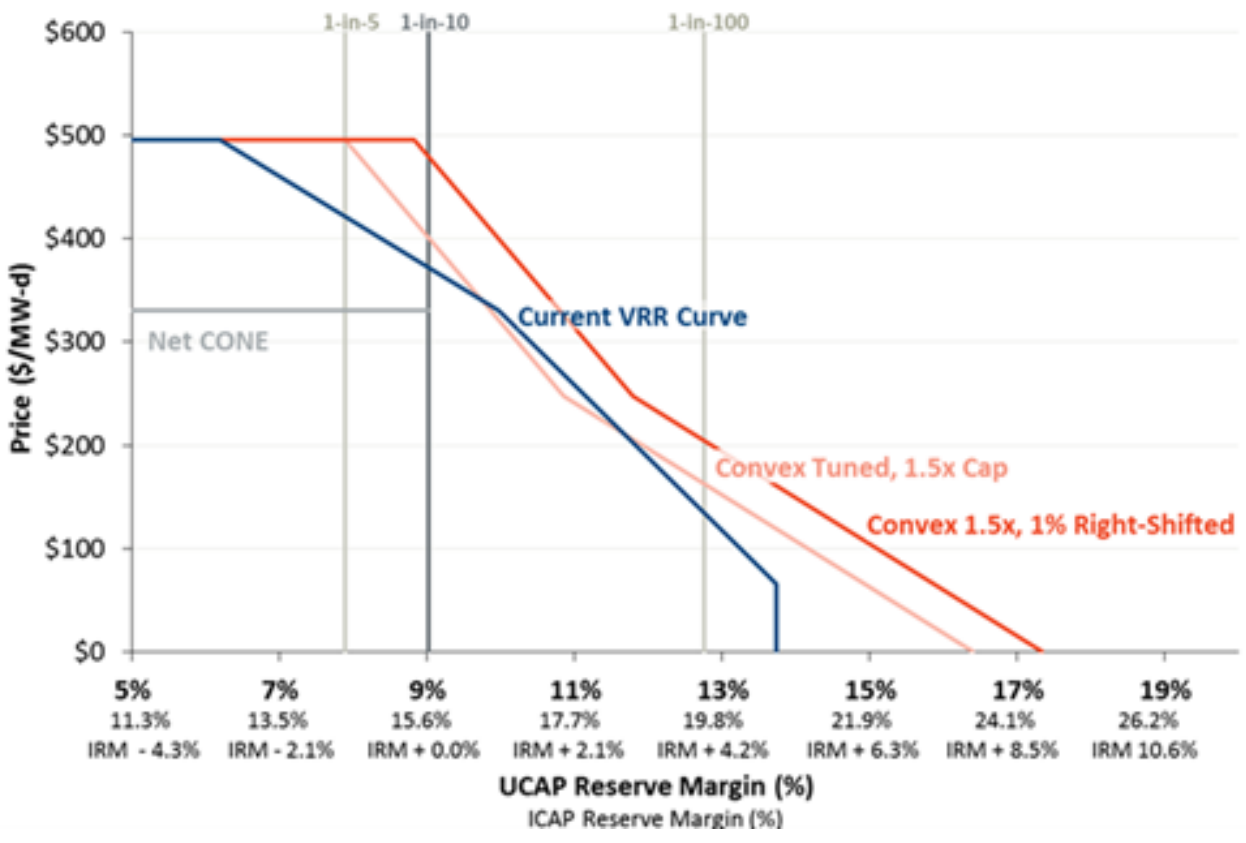

Figure 6. Variation of VRR curve across PJM over time

"Current" refers to the VRR curve in 2014 used in the 2017/2018 auction. The curve used by PJM in 2015 for the 2018/19 auction is to the far right (Convex 1.5x, 1\% RightShifted). Two metrics of capacity are shown on the x-axis: the installed (summer) capacity (ICAP) and the unforced capacity (UCAP). UCAP rather than ICAP is representative (as defined in PJM) of the maximum available capacity. For example, the UCAP rating for thermal units is determined by reducing its availability by its forced outages rate (e.g., $4 \%$ ). Likewise solar and wind nameplates are multiplied by 0.38 and 0.13 , respectively, to determine the contributions that are eligible to meet capacity requirements (PJM 2015). Figure source: Pfeifenberger et al. (2014).

Such gradient-reduction changes in VRR demand curve designs can have a significant impact on capacity prices paid for a given level of RM; all else being equal, this change increases capacity payments for margins above the target RM while decreasing those below it. However, in 2014 in PJM, there was no significant reduction in capacity payments under the new VRR demand curve for the most recent change in PJM, because the curve also shifted $1 \%$ to the right. To provide higher payments at higher RM, while limiting the relative size of the increase at lower RM, the curve's shape was also switched from concave to convex (Figure 6: curves denoted "Current VRR Curve," "Convex Tuned, 1.5x Cap," and "Convex 1.5x, 1\% Right-Shifted"). The August 2015 auction for delivery in 2018/2019 (which reflected these VRR demand curve changes) saw a $35 \%$ increase in capacity prices (compared to the prior year) to $\$ 165 / \mathrm{MW}$-day (or $\$ 60 / \mathrm{kW}$ year) for most of the RTO even though the supply cleared with a $19.8 \%$ RM, $4.1 \%$ in excess of the target RM (Heidorn and Herel 2015) and similar to the RM in 2014. These types of decisions often reflect a balance of stakeholder interests and differences. Some stakeholder groups representing consumer interests expressed concerns with the resulting increase in capacity prices. As Heidorn and Herel (2015) noted: 
For the second time in less than a year, consumers in the state-first in central and southern Illinois and now in northern Illinois - face significantly higher electric bills because of a flawed power-pricing system," said CUB Executive Director David Kolata, in a reference to MISO's capacity auction results in April, which saw a nine-fold increase in Illinois. ..."Illinois' electricity market is not working well for consumers. ...

This price spike is one more red flag that the rules governing the capacity auction open the door for power generators like Exelon, NRG and Dynegy to make windfall profits.

\section{Net CONE Reference Technologies}

Two key issues associated with choosing a reference technology were raised in our interviews and the broader literature: 1) choosing a reference technology based on the lowest capital cost to provide capacity might lead to overpayment of other technologies if they have a lower net CONE, and 2) this approach may favor selection of one technology or a few technologies when a larger technology mix may be more desirable from the perspective of improving system operation and reliability, encouraging diversity, and providing system flexibility for the purposes of resiliency given the large uncertainty over future cost drivers, such as fossil fuel prices, and if and when any form of carbon regulation is imposed. ${ }^{15}$

Typically, the reference technology chosen to estimate net CONE has been a frame CT, which has the lowest capital costs (on a $\$ / \mathrm{kW}$ basis compared to more efficient aero-derivative CTs or CCGTs) (Newell et al. 2014). However, a frame CT is likely to dispatch at relatively high energy prices owing to its low efficiency compared to other technologies such as aero-derivative CTs or CCGTs. In addition, these technologies may have a lower net CONE, despite having higher capital costs, because they may generate higher net revenue from higher utilization and greater efficiency. This seems to have been the case for the past 6 years of auctions in PJM, which has committed to build more new CCGT capacity than CT capacity for the 2013/2014 to 2018/2019 commitment periods (Table 2). Figure 5 also shows this effect, with the fraction of annualized capital recovery for new generation being higher for CCGTs than CTs for all of the last 6 years (between 2009 and 2014) and with a difference of nearly 50\% in 2 out of the last 3 years.

Because of these types of issues, there has been a debate over the choice of the appropriate reference technology and whether it should be based on lowest capital costs, lowest net CONE, the number of installed units (which may correspond to the technology with the lowest net CONE), or a combination of these criteria. Pfeifenberger et al. (2014) explore this question in some detail. In recent years, considerably higher levels of CCGT than CT construction by merchant generators in PJM has put in question whether new CT plants are suitable as an economically viable reference technology and can provide sufficiently reliable cost data. The Brattle Group, acting as an independent consultant for PJM, suggested a net CONE be based on a mix of CCGTs and CTs in part to reflect the observation that more CCGT than CT capacity was installed in recent years (Pfeifenberger et al. 2014). Pfeifenberger et al. (2014) argue that relying

\footnotetext{
${ }^{15}$ For example, future higher natural gas prices or internalization of the cost of carbon emission would both increase the relative economic attractiveness of a CCGT compared to a CT.
} 
on a net CONE average of technologies that are most likely viable for merchant investments may stabilize capacity prices and resource adequacy by mitigating periodic short-term deviations from the long-run equilibrium (due to unusual market conditions or estimation errors) and diversifying the risk of estimation error. However, PJM decided to continue using CTs as the basis for its net CONE calculation. As noted in Boshart (2014):

The RTO reasoned that the CONE for a combustion turbine is more accurate than for a combined cycle plant because it is less reliant on uncertain future energy revenues. Moreover, PJM said the CONE for both types of plants should be comparable given that the actual clearing levels in the RPM auction "ultimately will reflect the actual marginal resource, regardless of resource type."

The use of a reference technology based on the lowest net CONE may lead to the exclusive or dominant building of a single technology, even though a mix of technologies may be more desirable from a system perspective. ${ }^{16}$ One of our interview participants suggested that, while RTO/ISO markets may favor one technology in this way, these markets tend to self-correct over time. For example, if the net CONE with a CT reference technology encouraged CCGT entry, one might expect the increases in CCGT capacity to result in diminished energy prices over time. In consequence, this may make additional CCGTs less attractive relative to additional CTs.

There are other reasons for considering why the net CONE calculation based solely on a specific technology may not be optimal from a system-wide perspective. These include difficulty in setting energy, AS, and capacity payments adequately to reflect the true marginal value of new generation to the system. When considering the impact of higher-penetration VRE, Felder (2011) notes: "The combination of price recovery mechanisms for energy, capacity, renewable resources, emissions allowances, energy efficiency and demand response, however, interact in important and complex ways" and that "much more thought needs to be given to whether the combination of these pricing mechanisms provides efficient price signals from a societal perspective." In a similar vein, Borenstein and Bushnell (2015) argue, "Economic and technical integration of these intermittent renewable generation resources is likely to be one of the principal challenges facing the electricity industry in the next few decades." As an example, Borenstein and Bushnell (2015) point to a situation under high photovoltaic (PV) penetration in which "even if solar generation were perfectly forecastable, the rapid drop in net demand as the sun rises and increase in net demand as the sun sets would be difficult to meet with the current mix of gas-fired generation in California," and the most cost-effective solution might involve running more gas generation during the day and curtailing PV (Borenstein and Bushnell 2015). ${ }^{17}$

\footnotetext{
${ }^{16}$ Lower-cost forms of capacity, such as demand response and energy efficiency, are desirable and have been increasingly observed in many markets.

${ }^{17}$ As depicted by the so-called "duck curve," which shows "forecasted total demand and net demand for the California electricity grid on a sunny spring day with high penetration of solar PV" (Borenstein and Bushnell 2015).
} 
Table 2. Breakdown of Incremental Capacity Additions in PJM from 2007/2008 to 2018/2019

\begin{tabular}{|c|c|c|c|c|c|c|c|c|c|c|c|}
\hline & Delivery Year & CT & CCGT & Diesel & Hydro & Steam & Nuclear & Solar & Wind & $\begin{array}{l}\text { Fuel } \\
\text { Cell }\end{array}$ & Total \\
\hline \multirow{12}{*}{$\begin{array}{l}\text { New } \\
\text { Capacity } \\
\text { Units } \\
\text { (ICAP } \\
\text { MW) }\end{array}$} & $2007 / 2008$ & & & 18.7 & 0.3 & & & & & & 19.0 \\
\hline & $2008 / 2009$ & & & 27.0 & & & & & 66.1 & & 93.1 \\
\hline & $2009 / 2010$ & 399.5 & & 23.8 & & 53.0 & & & & & 476.3 \\
\hline & $2010 / 2011$ & 283.3 & 580.0 & 23.0 & & & & & 141.4 & & $1,027.7$ \\
\hline & $2011 / 2012$ & 416.4 & $1,135.0$ & & & 704.8 & & 1.1 & 75.2 & & $2,332.5$ \\
\hline & $2012 / 2013$ & 403.8 & & 7.8 & & 621.3 & & & 75.1 & & $1,108.0$ \\
\hline & $2013 / 2014$ & 329.0 & 705.0 & 6.0 & & 25.0 & & 9.5 & 245.7 & & $1,320.2$ \\
\hline & $2014 / 2015$ & 108.0 & 650.0 & 35.1 & 132.9 & & & 28.0 & 146.6 & & $1,100.6$ \\
\hline & $2015 / 2016$ & $1,382.5$ & $5,914.5$ & 19.4 & 148.4 & 45.4 & & 13.8 & 104.9 & 30.0 & $7,658.9$ \\
\hline & $2016 / 2017$ & 171.1 & $4,994.5$ & 38.3 & & 24.0 & & 32.1 & 54.3 & & $5,314.3$ \\
\hline & $2017 / 2018$ & 131.0 & $5,010.0$ & 124.8 & 6.0 & 90.0 & & 27.0 & & & $5,388.8$ \\
\hline & $2018 / 2019$ & $1,032.5$ & $2,352.3$ & 29.9 & & & & 82.8 & 127.1 & & $3,624.6$ \\
\hline
\end{tabular}

Source: PJM (2015). 
The role of flexible capacity may become increasingly important with increasing VRE, while current price signals may be too blunt, for example, to distinguish the relative value of CCGT and electricity (or energy) storage. Electricity storage, for example, may be able to optimize operation based on market prices between providing capacity and performing arbitrage between peak and off-peak electricity prices. However, storage can also be operated in other ways that might provide greater system-wide benefits but that are not easily valued or captured by storage, such as benefits that may be associated with distribution and transmission deferral and reduced stop-starts for the rest of the thermal generation (Sioshansi et al. 2012, Denholm et al. 2013). ${ }^{18}$

\section{Net CONE: Historical vs. Forward Looking}

Net CONE is typically estimated in advance of the delivery period. There are two principal approaches to estimating net CONE: 1) based on historical cost, and 2) based on a forwardlooking assessment. For example, PJM calculates future net CONE based on a historical 3-year average, whereas ISO-NE applies a forward-looking assessment based on the forward prices of natural gas and spark spreads for the reference technology.

The historical approach reflects actual experience of past system operation and energy prices, and averaging over 3 years aims to better reflect the effects of year-to-year variation. However, a weakness of this approach is the effective 4.5-year lag between price setting and the delivery period. As noted by Pfeifenberger et al. (2014), "With a four- to six-year delay between the historical years and the delivery year, the historical average may not be representative of evolving market conditions." For example, the lower natural gas prices due to shale gas since 2009 - a phenomenon that a historical approach would not have captured - may have contributed to the low capital recovery since 2009. As Bowring (2013) notes in a review of PJM:

The use of the net revenue estimate based on the average of three years of history, as is the current practice, can distort capacity market prices either above the competitive level or below the competitive level depending on the relationship between historical revenues and actual revenues during the delivery year. If net revenues were high in some or all of the historical period and are low in the actual delivery year, the capacity clearing price will be biased downward.

In a dynamic market with highly volatile fuel prices, a forward-looking assessment as implemented by ISO-NE and suggested by others (e.g., Bowring 2013, Pfeifenberger et al. 2014) may be better suited to estimating future net CONE. Future differences in energy revenue and net revenue between now and the delivery year may then be at least partly hedged using natural gas or other forward contracts. ${ }^{19}$ Nevertheless, PJM has decided to retain the historical approach. In part this may reflect that implementing

\footnotetext{
${ }^{18}$ This would require developing AS that paid storage more to provide these system benefits that arbitrage through energy differences and capacity payments.

${ }^{19}$ Such hedging will not completely eliminate net revenue risk for a number of reasons, and it will vary by generator type. First, natural gas prices are likely to be strongly but not perfectly correlated to energy prices. For example, a study of storage in PJM (Sioshansi et al. 2011) found that the weekly correlation of natural gas prices with peak and off-peak electricity prices was 0.63 and 0.58 , respectively (over a 3.5-year period between 2005 and 2009). Net revenue on a technology-specific basis will also be affected by utilization, which may be affected by fossil fuel prices (e.g., if coal and gas switch places on the margin) or demand (which can be significantly affected by actual vs. average or expected weather conditions and other factors).
} 
changes in 2014 would have been unfavorable to generators, because the most recent historical 3-year average for natural gas prices is lower than the current forward price in 2018. To illustrate this point further, Figure 7 depicts the difference in the actual price of natural gas from two methods of natural gas price projection ("historical" and "forward") for delivery during 2005-2013. For the purpose of this illustration, the historical natural gas price projection is composed of an unweighted average of natural gas prices for the electric sector reported by the U.S. Energy Information Administration (EIA 2015a, $2015 b$ ) for the 3-year period preceding the year when the decision about capacity payments was made. For instance, for delivery in 2010, decisions about capacity payments were made in 2007 with the projected natural gas price calculated as the average of the natural gas price in years 2004, 2005, and 2006. The forward price method in this simple illustration relies on EIA (2015a, 2015b) projections made 3 years earlier for the price of natural gas in the delivery period. As shown in Figure 7, the actual natural gas price between 2005 and 2008 was typically in the range of \$7-\$9/MMBtu. Between 2009 and the present, the price of natural gas dropped substantially owing to the availability and production of shale-based natural gas. The two sets of bars in Figure 7 show the differences between the actual price of natural gas in the delivery year and the natural gas price projections under the historical and forward approaches. Clearly the differences between these estimates can be substantial in both cases on a \$MMBtu basis, though the forward price approach tends to have smaller deviations from the actual natural gas price compared with the historical approach.

Another consideration may be the different views of stakeholders. PJM's chief economist noted - when departing from a few consultant recommendations, including the suggestion to retain use of the historical average - that this "in large part, resulted from the stakeholder process that is an essential component of the periodic review of those parameters" (PJM 2014d).

In this example, but also more generally, the prospect of changing methods raises the issue of how to handle potential transition costs associated with ongoing but uncertain future rule changes that may benefit long-term market operation but may increase short-term costs to investors, consumers, or both. One possible solution, even if it made future costs to consumers more uncertain, would be for the RTO to perform "make whole" net adjustments. Retrospectively correcting for the effect of uncertainty has significant precedent not only in regulated utilities (in the form of fuel price adjustments), but also in restructured markets through similar payments. A transition cost perspective may also be useful when considering some of the challenges associated with higher VRE penetration (see Text Box 1 in Section 4). 


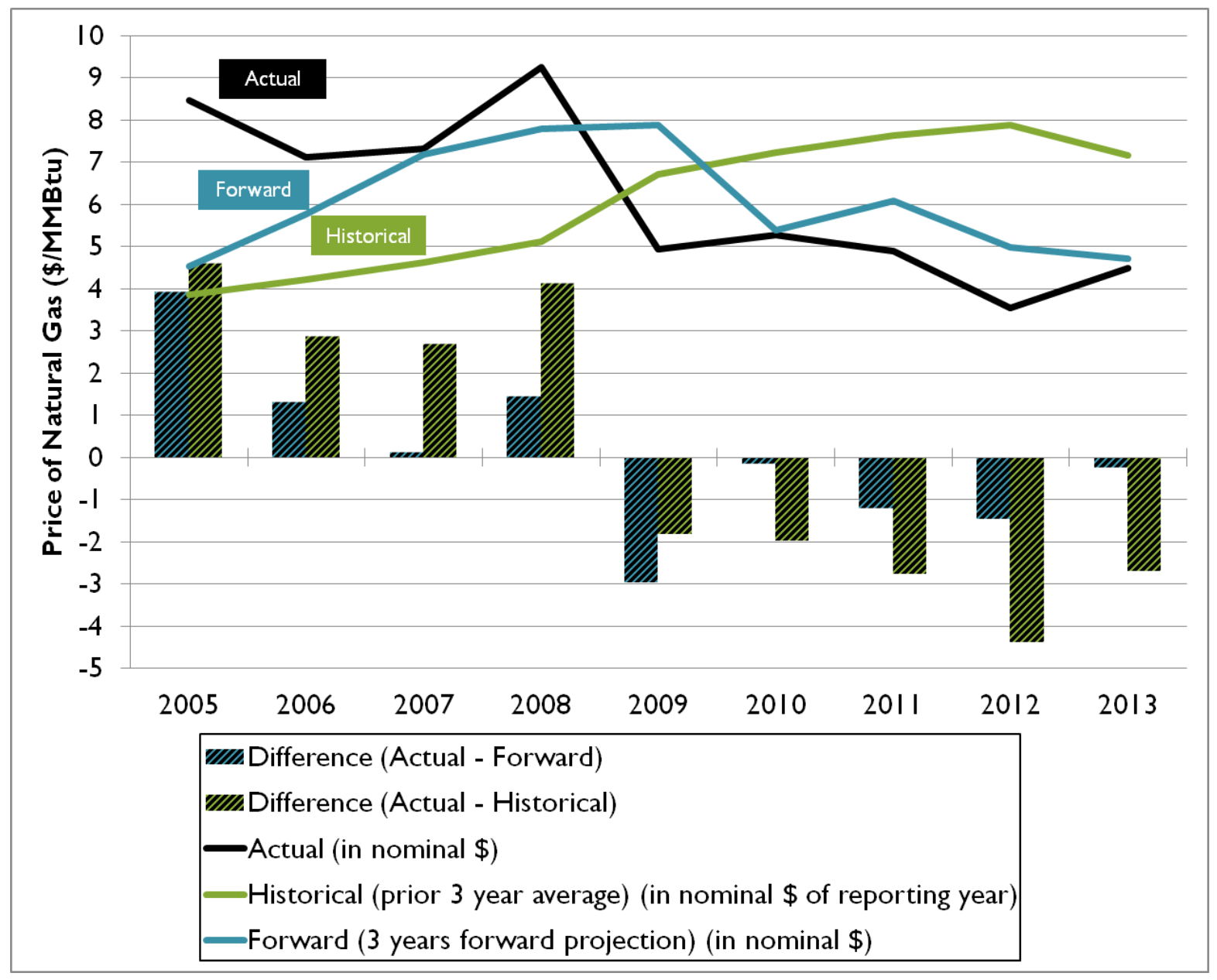

Figure 7. Actual natural gas prices for the electric sector and differences between actual and projected natural gas prices in the delivery year using 1) historical 3-year average prices, and 2) forward prices, both estimated 3 years in advance of the delivery year.

Source: Based on EIA data (EIA 2015a, EIA 2015b).

\subsubsection{Commitment Periods}

Energy investments are capital intensive, and, from an investor's perspective, greater revenue certainty is desirable. This has made fixed-price power-purchase agreement (PPA) bilateral contracts prevalent with VRE and, to some degree, with conventional generation, even in restructured markets (Caplan 2012). Until recently, ISO/RTO auction commitment periods for delivery have typically been defined for a 1-year period. According to the American Public Power Association (APPA 2015b), this lack of future revenue certainty limits new builds, and "procuring capacity through long-term bilateral contracts and ownership is important for maintaining adequate capacity, and necessary to obtain financing for new power plants, including nuclear and renewable energy projects.” On the other hand, Bowring (2013) comments that such concerns may "ignore the fact that long term market based contracts are available, including the sale of energy market price hedges and tolling agreements, which reflect market participants' views of future market condition." 
Reflecting the need for greater revenue certainty for new generation across RTOs/ISOs and internationally, there lately has been a trend outside PJM - at least for new generation - towards extended commitment periods under a fixed price with adjustments for inflation and a variety of conditions. For example:

- Single-year commitment period for capacity (PJM)

- 1- or 5-year commitment period for new capacity (generators have a choice) with capacity payments adjusted for inflation; current proposal to extend to 7 years (ISO-NE)

- 15-year commitment period for new capacity, 3 years for retrofits, and 1 year for existing generation (in the United Kingdom).

There is a tradeoff between the desires of investors and the RTO and consumers in choosing an adequate commitment period. With a shorter commitment period there is considerable revenue uncertainty about future capacity payments, while longer commitment periods provide greater revenue certainty to generators and may lower the cost of capital. ${ }^{20}$ However, longer contracts may shift more of the risks towards consumers, because future need for capacity is uncertain, and this uncertainty increases as the commitment period extends further into the future. The financial implications of these market design choices may be considerable for consumers and investors, because generators may lock in their commitment for multiple years, while market fundamentals (such as fuel prices and the need for capacity) can change during the commitment period.

This lack of certainty about the future net revenue from energy, AS, and capacity payments means that whether existing plants remain generating or retire, or whether potential new plants are built or not, depends on future market expectations. In their analysis of the UK capacity auction in 2014 for 2018/2019, Frontier/LCP (2015) note that "almost $10 \mathrm{GW}$ of existing capacity has missed out on a capacity contract, just under $17 \%$ of the capacity which participated. These power plants now face an uncertain future, and many may face closure. In contrast, $2.9 \mathrm{GW}$ of new build capacity received contracts, including a large number of small projects" (Figure 8).

\footnotetext{
${ }^{20}$ Although long commitment periods provide revenue certainty, they do not eliminate net revenue risk because of the remaining uncertainty related to energy and AS revenue.
} 


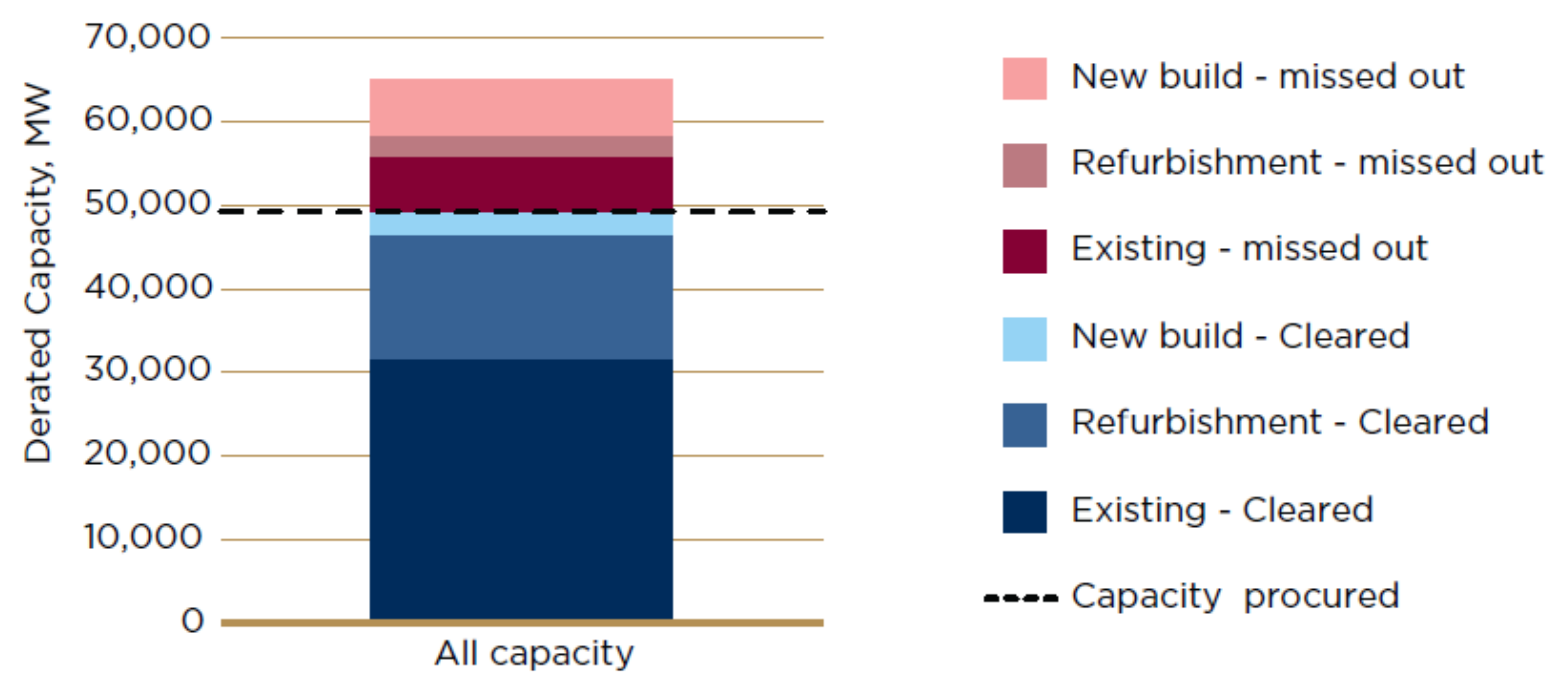

Figure 8. Existing and new capacity that cleared and missed out in UK 2014 capacity auction for 2018/19

Source: Frontier/LCP (2015)

Because of the bidding behavior and associated expectations in the United Kingdom, similar types of existing plants and new plants differed in whether they retired or, in the case of new plants, in whether they would be built (Frontier/LCP 2015):

Given the low clearing price many will have been surprised to see a new build CCGT clearing in the auction. The new Trafford power station, with a total capacity of 1,880 MW, will become one of the largest GB [Great Britain] power stations. In comparison Carrington, due for completion in 2016, has missed out perhaps in the expectation of higher clearing prices in future auctions. Given that a significant proportion of the cost of Carrington construction is already sunk it highlights how the different views of operators and investors can lead to counterintuitive outcomes. Time will tell which decision will prove to have been most judicious.

The impacts of such decisions made under uncertainty, due to possible premature retirements or unprofitable new generation, on the future returns to generators and costs to consumers are worth careful analysis. In fact, construction of the Trafford plant was recently delayed, with the developer citing the difficulty obtaining financing caused by regulatory interventions and low energy prices that resulted in part from subsidized VRE and broader uncertainties about future policy (discussed in more detail in Section 4) (Gosden 2015).

\section{Definition of and Payment for Capacity Products}

In our interviews and in the literature, a common theme is whether existing and new generation assets should receive the same capacity payments. Some have suggested that (at least until recently) capacity payments were not sufficient to incentivize new capacity in RTO/ISO markets, while the payments offered "windfall" profits to existing generation that may have been built at substantially lower capital costs and is often fully depreciated (APPA 2015a). APPA is 
concerned less about whether capacity payments should be equal or not and more about the possible lower efficiency of equal payments compared with capacity commitments arranged under bilateral contracts. Caplan (2012) showed that bilateral contracts for new capacity have been extremely prevalent for both VRE and conventional generation in both regulated and restructured markets. In restructured markets this may be partly related to the uncertainty of future capacity payments.

More generally, there are two elements to this argument for reducing capacity payments to existing assets. On one hand, capital costs from existing generation are already sunk, and whenever a plant chooses to run it is making a profit. On the other hand, in a market regime with price caps, lack of demand-side response, and high reliability requirements, revenue from energy alone is unlikely to allow full capital cost recovery. Not allowing existing plants some form of capacity payments would likely limit new entry, because today's new entrant is tomorrow's existing plant.

However, even if some form of capacity payment is required, why pay the same amount to new and existing capacity if the purpose is to fill the missing money "gap" for new entry? The net CONE needed to incentivize an existing plant and cover its capital cost recovery might be substantially lower. For example, a 20-year-old plant that is otherwise identical to a new plant might cost $40 \%$ less owing to inflation, ${ }^{21}$ and, more broadly, returns on a fully depreciated or refurbished plant might be much higher. These potentially greater returns for existing and refurbished generation (as well as demand-side management) may lead to windfall profits. This may be thought of more in terms of a "distributional" rather than a purely economic question (Cramton and Ockenfels 2012).

A number of our interview participants quoted "one service, one price" as a "bedrock" economic principle that has broad acceptance. Under such an arrangement, older assets can receive a higher rate of return compared to new technologies. For fully depreciated or refurbished plants, this can lead to much higher returns, and this may be inherent in the nature of competitive markets. ${ }^{22}$ Nevertheless, the three examples below were raised in discussions related to the degree this principle of one price holds in practice:

1. Germany is an energy-only market (see Section 4) where high levels of renewable energy have suppressed energy prices to the point that some existing generation may not even be covering its fixed costs (Weiss 2014). There has been significant debate about how to respond to this, and strategic reserves of some capacity were implemented as part of Germany's recent electricity market reform (see Text Box 1 for more details). Any decision to pay only some of the generation for capacity would effectively create different prices for the same or very similar services.

\footnotetext{
${ }^{21}$ For example, the consumer price index increased 37\% (from 148.2 to 236.7) between 1994 and 2014.

${ }^{22}$ However, one interviewee discussed this point in relation to transition costs. In general, capital recovery in a restructured market is not guaranteed, and all units receive the same price for the same service. However, it is less clear whether this should also apply to generation for which capital was largely or completely recovered under a regulated cost-plus system. Allowing such plants to capture their capital again would produce windfall profits at the expense of the consumer, who paid the capital and a fair rate of return in earlier years. This again suggests that considering a transition cost viewpoint is important.
} 
2. The most recent ISO-NE auction resulted in different prices for new and existing capacity, because the auction process did not produce a competitive supply of new generation. A second auction later procured new generation at a higher price of more than $\$ 200 / \mathrm{kW}$-year - well in excess of the annualized capital cost for a new CT, even for one that never or very rarely ran. Had this second price been applied to all generation, the cost to consumers would have been much higher. ${ }^{23}$ In justifying these price differences, ISONE (2015a) noted, "The administrative pricing rules balance the interests of consumers paying for capacity by building in price protections under conditions of scarcity, and the interests of resources providing capacity by paying [a premium for new capacity]."

3. The idea of different contract lengths for the delivery of capacity for new generation, refurbishments, and existing generation also has pricing implications. If new generation is allowed a fixed price with inflation for 5, 7, or 15 years instead of a single year, then new capacity is effectively being priced differently in subsequent years compared with existing generation that is reliant on renewing new 1-year contracts.

Capacity prices may also vary by location or for different service at any given location. The need for capacity varies in different parts of a particular RTO, largely as a result of transmission constraints or a lack of locational pricing (Cramton and Ockenfels 2012). As a result, RTOs/ISOs are increasingly structured in multiple market zones, each with their own VRR demand curves. Figure 9 shows the different pricing for capacity in PJM regions from the most recent 2015 auction for delivery in 2018/19. The difference in prices for each region also reflects the introduction of a new performance-oriented capacity product with a premium of about \$15/MWday over the regular capacity product.

Another issue raised during our interviews relates to differentiated compensation for capacity types. For instance, capacity that offers a higher ability for ramping could be incentivized in an environment with higher VRE penetration. CAISO's introduction of a flexible resources requirement within its capacity market structure can be seen as a means to address this issuethough again this raises a set of choices about if and how to split payment for different services via annual capacity payments or nearer-term AS payments, and to reduce any risk of double counting.

\footnotetext{
23 "Administrative pricing rules for situations of inadequate supply were triggered in the Southeastern Massachusetts and Rhode Island (SEMA/RI) zone because just 7,241 MW of new and existing resources were competing, about $238 \mathrm{MW}$ short of the 7,479 MW needed for 2018-2019. As a result, the $353 \mathrm{MW}$ of new resources in the zone will receive the auction starting price of $\$ 17.73 / \mathrm{kW}$-month, while $6,632 \mathrm{MW}$ of existing resources will receive $\$ 11.08 / \mathrm{kW}$-month and $256 \mathrm{MW}$ of self-supply resources will not be paid through the FCM.” (ISO-NE 2015a)
} 


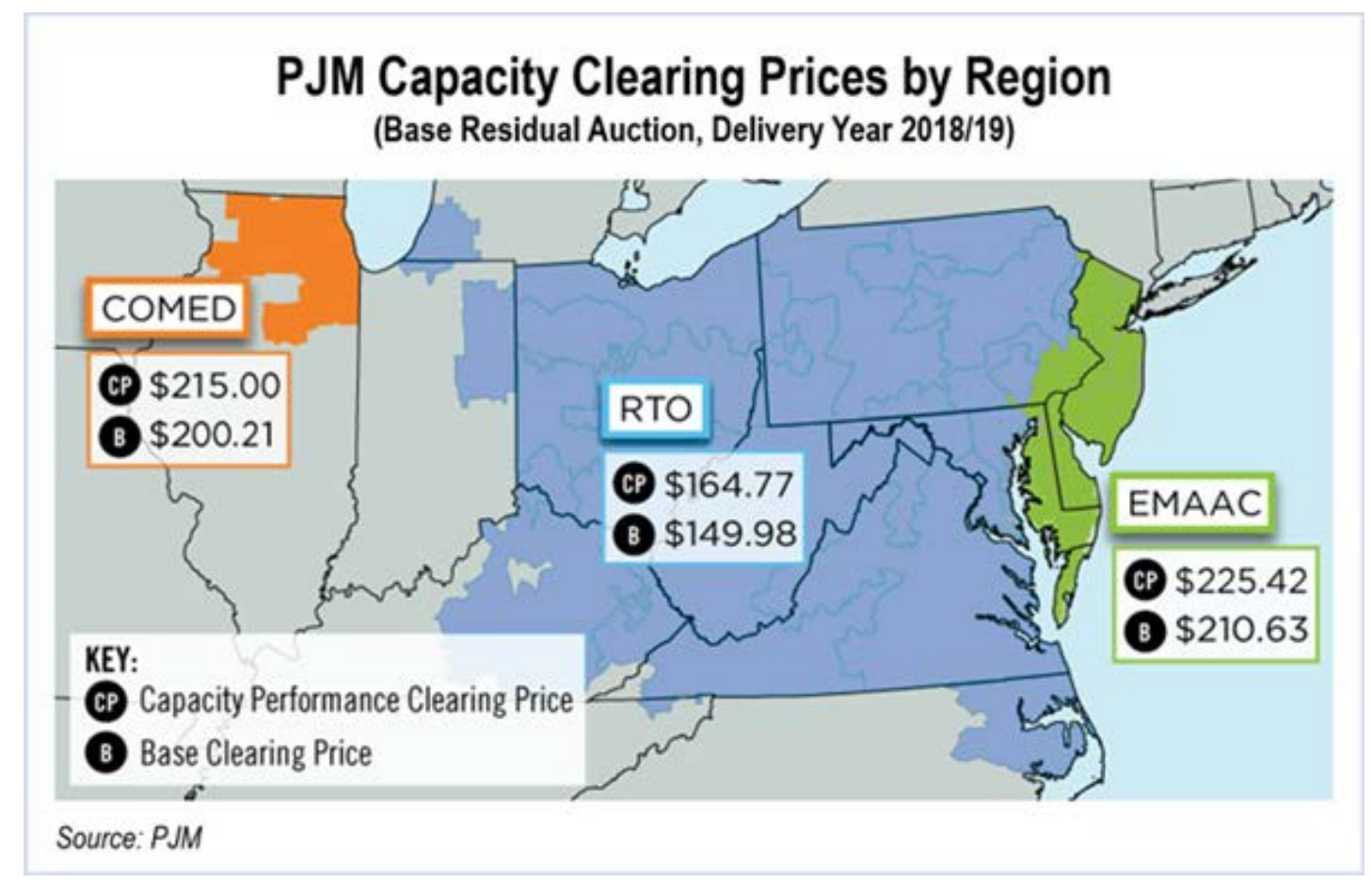

Figure 9. PJM capacity clearing prices (\$/MW-day) by region

Source: PJM (2015)

\subsubsection{Supplier Market Power}

Capacity markets face market power exercised by pivotal suppliers. Market power or related auction-design flaws could lead pivotal suppliers to raise offer prices and retire units prematurely. A pivotal supplier can be defined as a generation owner whose capacity is required in order for the market to clear (Bowring 2013). The ISO-NE market monitor noted (Patton et al. 2015):

...that when new suppliers are pivotal (must clear in order for ISO-NE to satisfy its capacity requirements) ... they have strong incentives to raise their offers and increase the capacity prices. This incentive is attributable to the higher revenues they will earn on other existing assets and the seven-year lock-in that extends the revenue benefits of raising capacity prices. Likewise, the report shows that existing suppliers that are pivotal have strong incentives to retire units that would otherwise be economic in order to increase capacity prices. Thus, it is important to evaluate the forward capacity market on an on-going basis and to identify factors that may inhibit participation by new resources or otherwise reduce competition. [Emphasis added.]

This matters because of the market monitor's "substantial competitive concerns regarding new suppliers' incentives to submit competitive offers" (Patton et al. 2015). APPA (2015a) also raises potential concerns about existing generators discouraging new entry to ensure higher energy prices while receiving capacity payments, noting that "owners of existing generation resources have a strong interest in the current regime, which prevents competition from new entrants and props up capacity prices.” 


\subsubsection{Impact of Stakeholder Interests, Political Intervention, and Interconnection Issues}

Our review of the literature and interviews indicates that capacity market designs often reflect the relative influence of different stakeholder groups. Some interview participants noted that the complex stakeholder process often produces tradeoffs that do not satisfy all parties, possibly resulting in regulatory imperfection (Cramton and Ockenfels 2012) and/or market distortion. These points have been integrated within our previous discussions about changing the VRR demand curve, deciding how to estimate net CONE, and choosing a reference technology for net CONE. A recent example illustrates the degree to which changes proposed in December 2014 for the residual base auctions in the commitment period 2018/19 were favored by different stakeholder groups (RTOInsider 2014):

...but agreement was nowhere to be found on changes to the variable resource requirement (VRR) curve. Proposals by PJM staff, Public Service Enterprise Group (Package B) and Dayton Power and Light (Package I) all received less than $50 \%$ support in sector-weighted votes of the Markets and Reliability Committee, with only the Transmission Owners and Generation Owner sectors showing heavy support. Virtually all members of the Electric Distributors and End User Customer sectors opposed the proposed changes and supported the status quo, which received a $56 \%$ vote overall.

Market rules are shaped by multiple factors, including policy, "administrative parameters" (Spees et al. 2013), stakeholder interests, learning, "political and regulatory opportunism" (Cramton and Ockenfels 2012), and path dependency. Spees et al. (2013) comment, when considering the shape of VRR curves, that "each markets curve also has some idiosyncratic features that are the product of stakeholder negotiation." One interview participant observed that "wholesale restructuring" rules for new capacity were often "added on" to an existing electric system framework, in which many of the capacity addition or retirement decisions were influenced by political intervention. The nature and direction of these interests going forward are uncertain and may change over time. The introduction and possible extension of VRE subsidies (PTCs, investment tax credits, FITs), carbon dioxide targets, or Germany's decision to "phase out" nuclear power by 2022-which was largely unexpected - are examples of such policy uncertainty. Cramton and Ockenfels (2012) note that these forms of uncertainty associated with political intervention can result in significant delays of new entry.

A recent survey in the United States by Bhagwat et al. (2016) of 22 participants found that one of the main concerns raised was interconnection issues and associated cross-border effects (such as imports or exports) where adjacent and connecting RTOs/ISOs may have different rules for capacity markets and/or be energy-only markets. This might allow some market participants to take advantage of these differences in ways that do not promote efficiency. ${ }^{24}$

\footnotetext{
${ }^{24}$ According to Bhagwat et al. (2016), the survey involves the participants answering 15 "open ended questions." The survey participants included consultants (44\%), regulators/government personnel (17\%), industry personnel (13\%), market operators (13\%), and academics (13\%) (Bhagwat et al. 2016).
} 


\section{Additional Challenges for Systems with High VRE Penetration Levels}

Previous sections primarily considered challenges related to capacity market design in ISOs/RTOs with relatively moderate VRE penetration levels. Higher levels of VRE, especially high wind and solar deployment, may amplify some of these challenges and impact market dynamics and costs significantly. In markets with a higher share of VRE (such as Germany), a significant suppression effect on wholesale energy prices has been observed owing to VRE's low variable operating cost and limited ability to provide capacity. This "merit order" effect associated with VRE energy price suppression has been widely discussed in the literature, and mitigating its effects while ensuring capacity-based reliability needs is a topic of considerable debate in Germany and elsewhere (e.g., Felder 2011, Traber and Kemfert 2011, Weiss 2014). Higher levels of VRE may also increase price volatility and reduce the utilization of conventional capacity. Lower energy prices and lower utilization may significantly reduce net revenue from wholesale energy markets for conventional generation and increase its reliance on capacity payments. More generally, the addition of any relatively firm capacity-including conventional generation, storage (Jenkin and Weiss 2005, Sioshansi et al. 2009), and demandside management - without offsetting retirement will also suppress energy prices owing to an increased RM. The price suppression due to VRE differs from that due to CTs, storage, or demand-side management, because VRE provides relatively little incremental capacity - though the differences between wind and solar are significant. For example, in its most recent capacity auction in 2015 for delivery years 2018/19, PJM uses a 13\% capacity credit (credited capacity as a percentage of nameplate capacity) for wind and a 38\% capacity credit for PV (PJM 2015). This corresponds to about one third of actual utilization for wind and more than $100 \%$ of actual utilization for PV to reflect the timing and statistical variation of generation, though these numbers may change with increasing VRE penetration, mitigation strategies, and advances in VRE technology. The treatment and choice of VRE capacity credits for use in the supply curve and when setting the target RM is important, because different definitions and choices may determine whether, for the same amount of conventional generation, the capacity market clears above or below the target RM. ${ }^{25}$

Views differ about the degree to which current capacity market mechanisms will function under higher VRE penetration. Some observers consider current energy and capacity markets adequately positioned for responding to additional VRE generation. They recognize the intricate linkage between energy and capacity markets, expecting two interrelated effects to offset each other under higher VRE penetration because: 1) as energy prices and net energy revenue in wholesale markets fall, ${ }^{26}$ 2) clearing prices and net revenue in capacity markets will rise to reflect an increase in net CONE. ISO-NE (2015b) recently commented on these effects:

The introduction of larger quantities of renewable resources would ... be expected to increase both CONE and offers from competitive capacity suppliers. CONE

\footnotetext{
${ }^{25}$ In a recent survey by Bhagwat et al. (2016), “41\% of respondents agreed that differences in calculating capacity credits could have an impact on capacity market performance (though) $23 \%$ were of the opinion that there is no or a minor impact, and 36\% were of no opinion. "Clearly the percentages themselves will reflect in part the professional breakdown of the participants responding (see also footnote 24).

${ }^{26}$ There are two effects on net revenue (without offsetting increases in demand): 1) lower prices for energy sold, and 2) less energy sold at these lower prices.
} 
would increase because additional renewable resources, which typically act as price takers in the energy market, would be expected to decrease energy prices and therefore net revenues for all resources in the energy market. This expected reduction would be reflected in reduced net energy market revenues calculated for the hypothetical new entrant as part of the CONE calculation. A reduction in net energy market revenues would increase the amount that a new entrant would require from the capacity market in order to move forward. What is true for the CONE calculation would also be expected to be true for the offers submitted by capacity resource owners: capacity market offers should rise as energy market revenues decrease.

The operational challenges associated with higher VRE, such as the potential need for more fast ramping services to respond to variable and uncertain generation, can arguably be compensated for with additional or refined AS. The degree to which increased capacity payments due to lower energy revenues might not be offset by increased AS for flexible ramping services is unclear. This would depend on market design choices, but, as is clear from Figure 5, this may require significant growth in net revenue for new AS services. Milligan et al. (2014) stress the need to consider the linkages between energy, AS, and net CONE carefully when determining system needs, though this may be challenging given the different temporal scales on which they operate. Others suggest that higher VRE levels may amplify the effects of any inadequacies in the existing market rules and possibly generate new ones (Riesz and MacGill 2013, Felder 2011). A system with more VRE resources and where capacity payments become a large fraction of net revenue for many generation technologies (Milligan et al. 2014) also raises a number of critical questions. BNEF (2015) notes that "capacity markets can ... be complex and costly, [and] have unintended or distortive consequences and they do not necessarily assist in the integration of renewables." As Felder (2011) notes, "The combination of price recovery mechanisms for energy, capacity, renewable resources, emissions allowances, energy efficiency and demand response, however, interact in important and complex ways," and "much more thought needs to be given to whether the combination of these pricing mechanisms provides efficient price signals from a societal perspective.” Borenstein and Bushnell (2015) note:

The low wholesale prices that resulted from expansion of subsidized renewables are not sufficient to cover the total cost of renewable or conventional sources, so the prominence of extra-market sources of revenue - such as above-market contracts and capacity payments - is likely to continue to grow. This will mean that even in the "market" states, the true cost of supply will increasingly diverge from the underlying price of the fundamental commodity, electrical energy.

A common motivation of restructured markets is to shift risk from consumers (characteristic of a regulated market) to shareholders of generation. The creation of capacity payments to fill the "missing money" gap involves a partial shift of risk back towards the consumers, and it further relies on a central regulatory authority to both design a VRR demand curve and estimate an adequate net CONE value; a poorly designed market may not only shift risks, but also increase them overall. As VRE penetration becomes greater and capacity payments make up a greater proportion of both new generator and existing generator net revenue, any inefficiencies or risks in the implementation of the capacity market may become more pronounced. Riesz and MacGill (2013) consider the role of capacity payments under high VRE and caution about capacity markets leading to "increasing prescriptive regulations" and "shifting decision making and risk 
management away from market participants to a central authority," which arguably constitutes a shift back to utility regulation schemes predating restructuring. They also discuss the challenges of estimating the appropriate capacity value at high VRE penetration levels and of providing technology-neutral decisions.

Potentially offsetting some of these effects, the effective capacity associated with VRE may be enhanced considerably by properly considering the coupling effects between solar and wind generation (due to lack of correlation) as well as the reduced variation in generation that may be possible by aggregating over wide geographic areas. However-as mentioned earlier in our discussion of storage and its ability to lower overall system cost by reducing start-stop costs of multiple generators - it is challenging to create responsive market rules that fully reflect systemwide benefits while allocating payments appropriately to the entities that provide them.

The short-term delivery commitment period of most annual capacity auctions may also bias investment against technologies with high capital costs unless they are able to sign long-term bilateral contracts to reduce risks. This applies not only to VRE, but also to other large-scale assets with high fixed capital-to-variable energy-cost ratios, like nuclear generation, that can provide capacity but typically require guaranteed long-term revenues to be financially viable (APPA 2015a, Weiss and Sarro 2013). In the view of APPA (2015b), "Procuring capacity through long-term bilateral contracts and ownership [is] important for maintaining adequate capacity, and necessary to obtain financing for new power plants, including nuclear and renewable energy projects."

Another related issue arises from the combined presence of capacity markets and significant numbers of subsidized bilateral contract agreements, which are a very common financial arrangement among VRE projects in the United States and elsewhere. These contracts for VRE, such as PPAs, rely on payments that are fixed and often subsidized. There are many welldocumented reasons to subsidize VRE, such as recognizing and internalizing the value of VRE's avoided carbon emissions, increasing VRE deployment and thus reducing both future capital and levelized costs (via learning, research and development, and other effects), as well as helping VRE to better compete with conventional generation that is subsidized or has been subsidized in the past. In regulated markets that operate on a cost-plus basis, the incremental costs of subsidies are shared by consumers. In contrast, in restructured markets, subsidized VRE generation may reduce energy prices and trigger higher capacity payments. Yet, given VRE's limited ability to provide capacity, this combination of lower energy prices and higher capacity prices might not produce optimal generation mixes under high VRE penetration. More specifically, the subsidization of such VRE contracts may distort the market structure and associated payments to generation. Recently in the United Kingdom, for example, the building of the Trafford CCGT plant was delayed - despite "winning" the capacity auctions - owing to difficulties in securing financing. The director of Carlton Power, which had intended to build the plant, said that "longterm political intervention through 'continuing direct subsidies for low carbon technologies such as wind, nuclear and solar' skewed the wholesale power market, making the price artificially low and making it harder to invest in gas plants" (Gosden 2015). Similarly, Germany's experience with high VRE penetration and substantial price suppression suggests that VRE incentive schemes and capacity market designs need to be carefully aligned to consider short-term and longer-term horizons. There has been considerable debate in Germany about the need for and 
design of a capacity market and whether it should distinguish between different capacity sources (Text Box 1).

\section{Text Box 1. Germany: A Market with High VRE Penetration}

As part of its electricity market liberalization in 1998, Germany established an energy-only market. Investments for electricity generation were primarily recovered through energy-based wholesale prices, which included an implicit compensation for available capacity. ${ }^{27}$ Since the early 2000s, the Renewable Energy Act (Erneuerbare-Energien-Gesetz) and FITs incentivized large-scale deployment of VRE, particularly solar and wind. The considerable share of VRE and the recent decision to phase out existing nuclear plants by 2022 has led to concerns about reliability and revenue adequacy for conventional generators. Wholesale electricity prices have dropped substantially, while retail prices have increased owing to FITs being paid by consumers through retail rates. This has resulted in revenue losses being incurred by conventional generators and large German utilities E.ON and RWE (Figure 10). The discussion about reliability and revenue adequacy is part of a larger trend within Europe to implement capacity remuneration mechanisms (for instance, in the United Kingdom, France, and Belgium).

In preparing a white paper for the German government, a comprehensive stakeholder process and various studies assessed options to ensure sufficient capacity for meeting electricity demand at all times. An impact assessment by Frontier Economics and Consentec (2014) assessed the following options:

1. Reserve (strategic reserve)

2. Decentralized capacity mechanisms with capacity obligations

3. Centralized capacity mechanism with tendering and reliability contracts

4. Central focused capacity mechanism.

It is important to note that options 1, 2, and, to a lesser degree, 3 offer different approaches to capacity payment and resource adequacy issues than the VRR mechanism discussed earlier in this report.

These options were evaluated based on effectiveness, efficiency, regulatory assessment, international integration, impact on competition, and reversibility/flexibility. The government white paper (BMWi 2015a) rejected the idea of a capacity market as part of Germany's "Electricity Market 2.0." Instead of pursuing a VRR approach with payments to all generators for capacity, the government suggests preserving the existing mechanisms of an energy-only market and introducing capacity reserve safeguards (option 1 above). This capacity reserve comprises $4 \mathrm{GW}$ from power stations that do not participate in the electricity market. The Federal Ministry for Economic Affairs and Energy has stated that "these power stations will be used only if, despite free price formation on the wholesale market and contrary to expectations,

\footnotetext{
${ }^{27}$ A capacity reserve mechanism ("Netzreserve") was formerly in place only in the southern part of Germany.
} 
supply does not cover demand at a particular time" (BMWi 2015a).

A traditional capacity market design was rejected on the basis of three primary reasons: 1 ) sufficient levels of existing capacity, 2) a general perception that capacity markets distort the market, and 3) cost effectiveness. Germany is expected to have a net increase in capacity of 1 GW through 2017 and capacity resources of $11.7 \mathrm{GW}$ in excess of estimated peak load by 2016 (DIW 2014)

The cost assessment from Frontier Economics and Consentec (2014) suggests that any of the capacity mechanism options were less cost effective than the strategic reserve and required more regulatory intervention. In addition, Cramton and Ockenfels (2012) note that Germany "might not [have looked] for long term solutions of the resource adequacy problem, but rather for targeted measures to supplement the current transition phase ... [in response to] the growth of renewables and insufficient transmission." The idea that it might be preferable or cheaper to pay transition costs for a situation - at least to a point - that may have come about in large part owing to VRE subsidies deserves careful consideration and cost-benefit analysis.

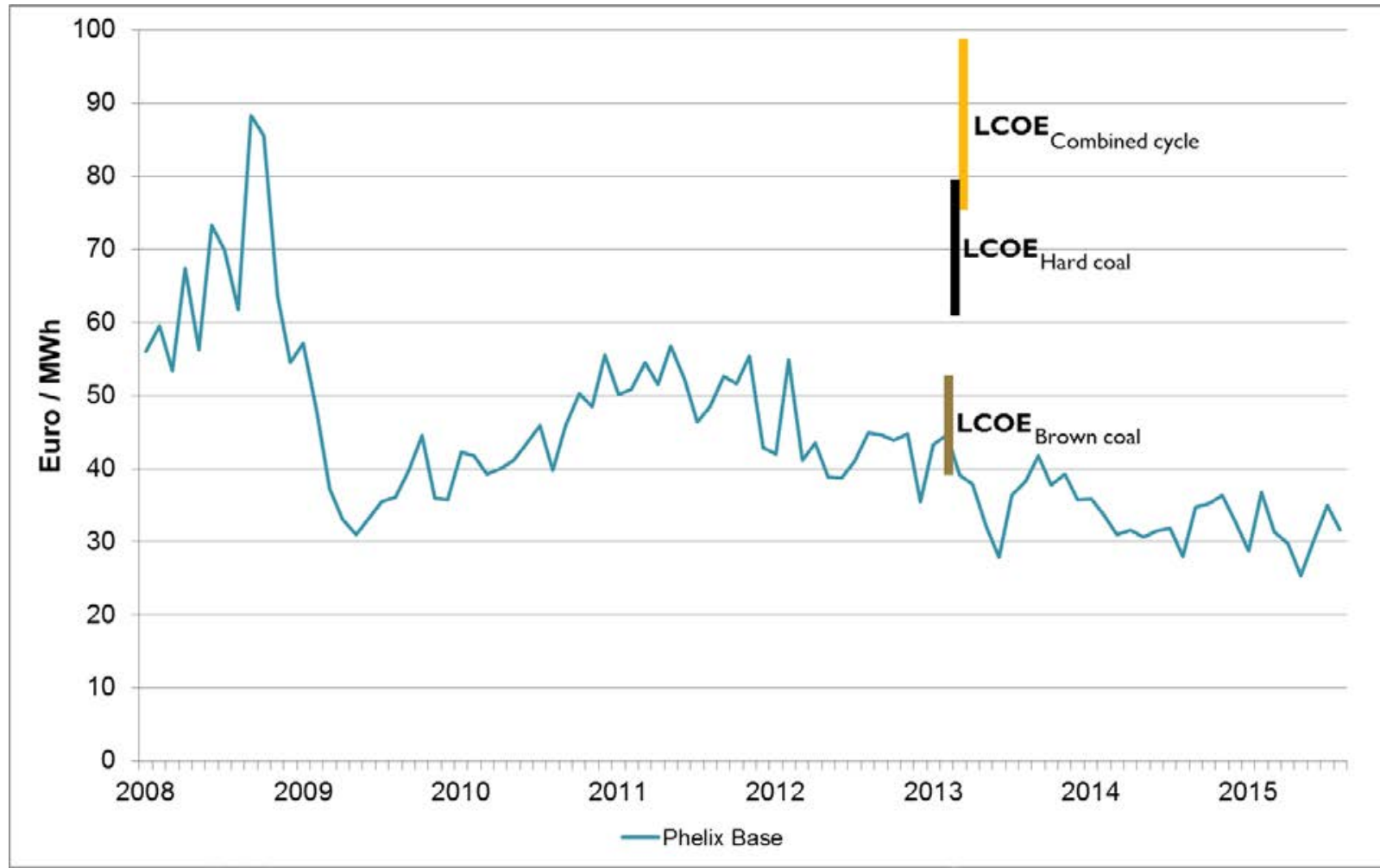

Figure 10. German wholesale electricity prices (Phelix Base, monthly averages) for 2008-2015 and estimated ranges for levelized cost of electricity (LCOE) of fossil fuel power plants constructed in 2013

Sources: German wholesale electricity prices: BMWi (2015b); LCOE: Fraunhofer (ISE) (2013). 


\section{Conclusions and Future Analysis}

There is significant variation in the implementation of capacity markets in the United States and elsewhere. Capacity markets are challenging to implement, because they are designed to meet an estimated future "missing money" gap in the net revenue needed to provide sufficient capacity for meeting reliability targets. The process for determining capacity payments typically involves using an administratively determined demand curve, which requires numerous choices about the curve's shape and height as well as what the curve represents (e.g., whether the reference technology for net CONE is a CT, a CCGT, or a combination of different technologies). We discussed differences across some capacity markets, including how they have evolved over time and how the current and future market design outcomes may reflect the interests of different stakeholder groups and history. While market evolution and refinement helps adapt a system to reflect market dynamics and learning, it also introduces risks to investors.

We also considered challenges specific to higher penetration levels of VRE. Higher VRE penetration may lead to the so called "merit order" effect, which can be expected to suppress both wholesale energy prices and energy sales by conventional generation. Under current market design, this effect likely can be mitigated in part by some combination of increased capacity payments and AS revenue. However, the resulting greater reliance on capacity markets and capacity payments for generator revenues, with their 3-year lead times over delivery, may amplify any inefficiency and costs associated with capacity price volatility and less than optimal market design choices. Regulatory intervention and the refinement of market rules to ensure adequate capacity payments and AS revenue may become more prevalent than under current market designs. Our review and discussion with market participants suggest challenges may remain in implementing capacity markets under high-VRE scenarios.

Our review also identified some areas for which additional analysis may be useful. One of the main challenges with designing and implementing capacity markets is that the future is inherently uncertain. In particular, analysis of alternative market design choices should recognize that the future distributions of certain variables - such as the likelihood, timing, and impact of carbon-based regulation and rulemaking, or fossil fuel prices over the next decade or more - may be unknown. A range of informed sensitivity analyses on net CONE and other key components of capacity markets, such as the shape of the VRR curve, can help characterize benefits, costs, and risks associated with different capacity market design choices, including under higher VRE penetration levels. Future analysis could also focus on the relationship between capacity payments and energy and AS revenue under high VRE penetration levels. In particular, it may be interesting to what degree AS payments can offset capacity payments in an environment with increased need for ramping and suppressed energy prices. Given the important role subsidies have had in VRE deployment across many markets, the potential role of transition costs in moving to more competitive capacity markets may also benefit from additional analysis. 


\section{References}

APPA (American Public Power Association). 2015a. "RTO Capacity Markets and their Impacts on Consumers and Public Power." APPA Fact Sheet, May 2015.

_ 2015b. "Money for Nothing in the Power Supply Business." APPA Issue Brief, October 2015.

Bhagwat, P.C., L.J. de Vries, and B.F. Hobbs. 2016. "Expert Survey on Capacity Markets in the US: Lessons for the EU." Utilities Policy 38: 11-17.

Blumsack, S.A., J. Apt, and L.B. Lave. 2006. "Lessons from the Failure of the U.S. Electricity Restructuring." Electricity Journal 19, no. 2: 15-32.

BMWi (German Federal Ministry for Economic Affairs and Energy). 2015a. "White Paper: Electricity Supply Remains Secure and Affordable." https://www.bmwienergiewende.de/EWD/Redaktion/EN/Newsletter/2015/07/Meldung/white-paper.html. Accessed September 24, 2015.

_.2015b. "Energiedaten und Analysen."

http://bmwi.de/DE/Themen/Energie/Energiedaten-und-analysen/energiedaten.html. Accessed December 2015.

BNEF (Bloomberg New Energy Finance). 2015. “Capacity Markets: A Primer.” BNEF, June 30, 2015.

Borenstein, S., and J. Bushnell. 2001. "Electricity Restructuring: Deregulation or Reregulation." Regulation 23, no. 2, 46-52.

_. 2015. "The U.S. Electricity Industry after 20 Years of Restructuring." Hass working paper, May 2015.

Boshart, G. 2014. "PJM Asks FERC to Approve Different Capacity Market Demand Curve from Brattle's." SNL Financial, September 26, 2014.

Bowring, J. 2013. "Capacity Markets in PJM." Economics of Energy \& Environmental Policy 2, no. 2: 47-64.

Caplan, E. 2012. "What Drives New Generation Construction? An Analysis of Financial Arrangements for New Electric Generation Projects in 2011." Electricity Journal 25, no. 6: 4861 .

Cramton, P., and A. Ockenfels. 2012. "Economics and Design of Capacity Markets for the Power Sector." Zeitschrift fuer Energiewirtschaft 36: 113-134.

Cramton, P., A. Ockenfels, and S. Stoft. 2013. "Capacity Market Fundamentals." Economics of Energy \& Environmental Policy 2, no. 2: 27-46. 
Denholm, P., J. Jorgenson, M. Hummon, T. Jenkin, D. Palchak, B. Kirby, O. Ma, and M. O'Malley. 2013. The Value of Energy Storage for Grid Applications. NREL/TP-6A20-58465. Golden, CO: National Renewable Energy Laboratory.

DIW (Deutsches Insitut fuer Wirtschaftsforschung). 2014. "Die Kontroverse um Kapazitaetsmechanismen fuer den deutschen Strommarkt." http://www.diw.de/documents/publikationen/73/diw_01.c.435670.de/diw_roundup 5 de.pdf. Accessed September 2015.

EIA (U.S. Energy Information Administration). 2011. "About $60 \%$ of the U.S. electric power supply is managed by RTOs." http://www.eia.gov/todayinenergy/detail.cfm?id=790. Accessed 2016.

_. 2015a. "Annual Energy Outlook Retrospective Review: Evaluation of 2014 and Prior Reference Case Projections."

https://www.eia.gov/forecasts/aeo/retrospective/pdf/retrospective.pdf. March 2015. Accessed 2016.

- 2015b. Before the Federal Energy Regulatory Commission, Docket No. ER14-2940000, Response. "Annual Energy Outlook 2015." http://www.eia.gov/forecasts/aeo/pdf/0383(2015).pdf. Accessed 2016.

Ela, E., M. Milligan, A. Bloom, A. Botterud, A. Townsend, and A. Levin. 2014. Evolution of Wholesale Electricity Market Design with Increasing Levels of Renewable Generation. NREL/TP-5D00-61765. Golden, CO: National Renewable Energy Laboratory.

Ela, E., M. Milligan, A. Bloom, A. Botterud, A. Townsend, T. Levin, and B. Frew. 2016. "Wholesale Electricity Market Design with Increasing Levels of Renewable Generation: Part 2 Incentivizing Flexibility in System Operations." Electricity Journal (forthcoming).

Felder, F.A. 2011. "Examining Electricity Price Suppression due to Renewable Resources and other Grid Investments." Electricity Journal 24, no. 4: 34-46.

FERC (Federal Energy Regulatory Commission). 2013. Centralized Capacity Market Design Elements. Commission Staff Report, No. AD13-7-000. http://www.ferc.gov/CalendarFiles/20130826142258-Staff\%20Paper.pdf. Accessed 2014.

- 2014. "Electric Power Markets: PJM." http://www.ferc.gov/market-oversight/mktelectric/pjm.asp\#MD. Accessed 2014.

Fraunhofer (ISE). 2013. Levelized Cost of Electricity. Renewable Energy Technologies Study. Edition: November 2013. https://www.ise.fraunhofer.de/en/publications/veroeffentlichungenpdf-dateien-en/studien-und-konzeptpapiere/study-levelized-cost-of-electricity-renewableenergies.pdf. Accessed 2016.

Frontier Economics and Consentec. 2014. Impact Assessment of Capacity Mechanisms. Report for the German Federal Ministry for Economic Affairs and Energy (BMWi). http://www.frontier-economics.com/documents/2014/09/security-of-supply-in-the-electricity- 
sector-impact-assessment-of-potential-capacity-reliability-mechanisms-for-germany.pdf. Accessed September 2015.

Frontier/LCP. 2015. "Review of the First GB Capacity Auction." Frontier/LCP Economics Review, January 2015.

Gosden, E. 2015. "Blow to UK Energy Plans as New Gas Plant in Doubt.” Telegraph, October $11,2015$.

Heidorn, R., and S. Herel. 2015. "Update: PJM Capacity Prices up 37\% to 165/MW-day." RTO Insider, August 21, 2015.

ISO-NE (ISO New England). 2015a. "Finalized Capacity Auction Results Confirm Resources, Prices for New England Power System in 2018-2019." Press Release, February 27, 2015.

_. 2015b. "Discussion Paper on New England's Capacity Markets and Renewable Energy Future." Memo to NECPUC, NESCOE and NEPOOL, June 3, 2015.

Jenkin, T., and J. Weiss. 2005. "Estimating the Value of Electricity Storage: Some Size, Location and Market Structure Issues." Presented at the Electrical Energy Storage Applications and Technologies Conference, San Francisco, CA.

Joskow, P. 2001. “California's Electricity Crisis.” MIT working paper, September 2001.

. 2008. "Capacity Payments in Imperfect Electricity Markets: Need and Design." Utilities Policy 16, no. 3: 159-170.

Lave, L., J. Apt, and S. Blumsack. 2007. "Deregulation/Restructuring Part II: Where Do We Go from Here?" Electricity Journal 20, no. 9: 10-23.

Milligan, M., B. Frew, A. Bloom, E. Ela, A. Botterud, A. Townsend, and T. Levin. 2016 "Wholesale Electricity Market Design with Increasing Levels of Renewable Generation: Part 1 Revenue Sufficiency and Long-Term Reliability." Electricity Journal (forthcoming).

Milligan, M., H. Holttinen, J. Kiviluoma, A. Orths, M. Lynch, and L. Soder. 2014. "Market Designs for High Levels of Variable RE.” NREL/CP-5D00-62280. Golden, CO: National Renewable Energy Laboratory.

Monitoring Analytics. 2014. "PJM State of the Market: 2013." http://www.monitoringanalytics.com/reports/pjm_state_of the market/2013/2013-som-pjmvolume1.pdf. Accessed 2015.

_. 2015. "PJM State of the Market: 2014."

http://www.monitoringanalytics.com/reports/PJM_State_of_the_Market/2014.shtml. Accessed 2015. 
NEF (New Economics Foundation). 2013. “Energy Round-up: Germany’s Renewables Revolution." http://www.neweconomics.org/blog/entry/energy-round-up-germanys-renewablesrevolution. Accessed December 2015.

NERC (North American Electric Reliability Corporation). 2015. "Planning Reserve Margin." http://www.nerc.com/pa/RAPA/ri/Pages/PlanningReserveMargin.aspx. Accessed September 2015.

Newell, S., and K. Spees. 2014a. Federal Energy Regulatory Commission, Docket ER14-2940000. Affidavit of Dr. Samuel A. Newell and Dr. Kathleen Spees on behalf of PJM Interconnection, LLC regarding periodic review of variable resource requirement curve shape and key parameters. September 25, 2014.

- 2014b. Before the Federal Energy Regulatory Commission, Docket No. ER14-2940000, Response of Dr. Samuel A. Newell and Dr. Kathleen Spees on Behalf of PJM Interconnection, LLC, regarding variable resource requirement curve, for use in PJM's capacity market. November 5, 2014.

Newell, S., J. Hagerty, K. Spees, J. Pfeifenberger, Q. Liao, C. Ungate, and J. Wrable. 2014. "Cost of New Entry Estimates for Combustion Turbine and Combined Cycle Plants in PJM." Prepared for PJM.

Patton, D.B., L. VanSchaick, P. Pallas, and J. Chen. 2014. "2013 Assessment of the ISO New England Electricity Markets, External Market Monitor for ISO NE." Fairfax, VA: Potomac Economics.

- 2015. "2014 Assessment of the ISO New England Electricity Markets, External Market Monitor for ISO NE.” Fairfax, VA: Potomac Economics.

Pfeifenberger, J., S. Newell, K. Spees, A. Murray, and I. Karkatsouli. 2014. Third Triennial Review of PJM's Variable Resource Requirement Curve. Cambridge, MA: The Brattle Group.

PJM. 2014a. "2017/2018 RPM Base Residual Auction Results." http://www.pjm.com/ /media/markets-ops/rpm/rpm-auction-info/2017-2018-base-residualauction-report.ashx. Accessed 2015.

- 2014b. "Submitted Revisions to the PJM Open Access Transmission Tariff to Revise Certain Elements of the Reliability Pricing Model." Wright \& Talisman PC. September 25, 2014. http://www.pjm.com/media/documents/etariff/FercDockets/1304/20140925-er14-2940-000.pdf. Accessed September 2015.

—. 2014c. "Resource Obligations in PJM." Training presentation, June 10, 2014.

- 2014d. "United States of America before the Federal Energy Regulatory Commission (PJM Interconnection, L.L.C.). Docket No. ER14-2940-000. Answer of PJM Interconnection, L.L.C. To Protests and Comments." 
_. 2015. "2018/2019 RPM Base Residual Auction Results."

http://www.pjm.com/ /media/879A2FA2A1794C7887A98686A70336D2.ashx. Accessed 2015.

Riesz, J., and I. MacGill. 2013. "100\% Renewables in Australia: Will a Capacity Market be Required." In Proceedings of the 3rd International Workshop on the Integration of Solar Power into Power Systems.

RTOInsider. 2014. "Members Deadlock on Capacity Parameter Change.” August 26, 2014. http://www.rtoinsider.com/pjm-deadlock-capacity-changes/. Accessed 2015.

Sioshansi, R., P. Denholm, and T. Jenkin. 2011. "A Comparative Analysis of the Value of Pure and Hybrid Electricity Storage." Energy Economics 33, no. 1: 56-66.

Sioshansi, R., P. Denholm, T. Jenkin, and J. Weiss. 2009. "Estimating the Value of Electricity Storage in PJM: Arbitrage and Some Welfare Effects." Energy Economics 31, no. 2: 269-277.

— 2012. "Market and Policy Barriers to Deployment of Energy Storage 6." Economics of Energy and Environmental Policy Journal 1: 47.

Spees, K., S. Newell, J. Pfeifenberger. 2013. "Capacity Markets: Lessons Learned from the First Decade." Economics of Energy \& Environmental Policy, Symposium on 'Capacity Markets,' 2, no. 2: 1-26.

SPP MMU (Southwest Power Pool Market Monitoring Unit). 2015 "2014 State of the Market." http://www.spp.org/documents/29399/2014\%20state\%20of\%20the\%20market\%20report.pdf. Accessed 2015.

Traber, T., and C. Kemfert. 2011. "Gone with the Wind? Electricity Market Prices and Incentives to Invest in Thermal Power Plants under Increasing Wind Energy Supply. Energy Economics 33: 249-256.

Weiss, J., and M. Sarro. 2013. The Importance of Long-Term Contracting for Facilitating Renewable Energy Project Development. Cambridge, MA: The Brattle Group.

Weiss, J. 2014. Solar Energy Support in Germany: A Closer Look. Cambridge, MA: The Brattle Group. 